Article

\title{
Experimental Comparisons and Evaluations of Different Types of DC-link Capacitors for VSI-Based Electric Compressors in Battery Electric Vehicle Systems
}

\author{
Namhun Kim ${ }^{1}$, Changju Park ${ }^{2}$, Sangshin Kwak ${ }^{2, *(\mathbb{D})}$ and Jeihoon Baek ${ }^{3}$ \\ 1 ESTRA Automotive System, Daegu 42981, Korea; cop1288@hotmail.com \\ 2 School of Electrical and Electronic Engineering, Chung-ang University, Seoul 06974, Korea; \\ fjfj123159@naver.com \\ 3 School of Electrical, Electronics and Communication Engineering, \\ Korea University of Technology \& Education, Cheonan 31253, Korea; jhbaek@koreatech.ac.kr \\ * Correspondence: sskwak@cau.ac.kr; Tel.: +82-2-820-5346
}

Received: 30 June 2020; Accepted: 28 July 2020; Published: 8 August 2020

\begin{abstract}
Electric compressor systems for air conditioning operations are an essential part in battery electric vehicle systems, which are not applicable to conventional belt-driven compressors due to no combustion engines. Three-phase voltage source inverters (VSI) and interior permanent magnet (IPM) motors are generally used for electric compressor systems in battery electric vehicles. Direct current (DC)-link capacitors are a critical component in the power converter systems, which affect the cost, size, performances and scale. Metallized polypropylene film capacitors are considered more reliable than conventional electrolytic capacitors for high temperature environments such as electric vehicle applications. This paper presents comprehensive comparisons and evaluations of electric compressors with two types of DC-link capacitors. Based on a $5 \mathrm{~kW}$ IPM motor drives and a VSI with a nominal DC voltage of $360 \mathrm{~V}$ for electric compressors, performances with electrolytic and film capacitors have been evaluated by experimental tests.
\end{abstract}

Keywords: electrolytic capacitor; metallized polypropylene film capacitor; voltage source inverter; electric compressor; battery electric vehicle

\section{Introduction}

In recent years, the necessity of environmental issues caused by global warming and pollution concerns have been getting accelerated research on battery electric vehicles [1-3]. The electric vehicles driven by only batteries without combustion engines require a variety of changes and modification in internal structures of vehicles. Compressors for air conditioning systems in vehicles are one of exemplary components, which have to dramatically altered in vehicle systems. Electric compressors have been employed in battery based electric vehicles due to their structures without engines, whereas compressors have been driven by powers of engines in internal combustion engine (ICE)-based vehicles. Electric compressor systems consist of three-phase voltage source inverters (VSIs) and interior permanent magnet (IPM) motors.

Direct current (DC)-link capacitors are a critical component in the power converter systems, which affect the cost, size, performances and scale. Metallized polypropylene film capacitors are considered more reliable than conventional electrolytic capacitors for high temperature environments such as electric vehicle applications [4]. Al-Cap is the most popular capacitor type used in power converter systems because of its high volumetric efficiency, low cost and available in an enormous range of 
capacities and sizes [5]. When selecting capacitors there are two main properties that need to be considered: breakdown voltage and capacitance. The selection of the initial capacitance value has to be taken into consideration of the normal and significant drop of capacitance in Al-Cap. If the over-voltages are occurred, the result is only a small decrease in the capacitance of the MPPF-Cap and never a significant capacitance drop or a breakdown [6]. Under the same situation, Al-Cap decreases a large amount of its capacitance, results in an unbalanced voltage and the capacitor can be in the short-circuit mode in the worst case [7]. In addition, Al-Caps need connected in series and require voltage balancing resistors to maintain the required high-level voltage in high power applications. This leads to a more complex bus structure and may cause additional damage when they fail. MPPF-Caps outperform Al-Caps in terms of ESR, self-healing capability, life expectancy, environmental performance, DC-blocking capability, ripple current capability and reliability [5]. However, the capacitance of the MPPF-Caps still cannot compete with Al-Caps, due to their relatively low volumetric efficiency and high cost. Several comparisons were presented about the performance between Al-Cap and MPPF-Cap. It demonstrates that the MPPF-Cap can handle more ripple current owing to the low ESR characteristic and their lifetime is about ten times longer than that of Al-Caps [5]. Furthermore, though the cost of Al-Caps, which is cheaper than the MPPF-Caps. However, the operational lifetime of the Al-Caps is much shorter than that of MPPF-Caps, and so will most likely require replacing at least once or twice within the lifetime of the power converter [8]. The MPPF-Cap has an operational lifetime more than ten times compared with Al-Caps. Then, the cost of replacement will outweigh the price difference between the different types of capacitors [9].

Figure 1 shows a block diagram of an electric vehicle with Full Automatic Temperature Control (FATC), which is a focus of study. FATC consists of an electric compressor and an inverter to drive the compressor. The electric compressors with the electrolytic capacitor and the film capacitor are evaluated in terms of capacitor characteristics, Root Mean Square (RMS) values of DC-link currents, ripple characteristics of capacitor voltage/current, power losses, and junction temperatures in this paper. The main contribution of this paper is to provide comprehensive comparisons and evaluations of electric compressors with two types of DC-link capacitors. For the purpose, based on a $5 \mathrm{~kW}$ IPM motor drives and a VSI with a nominal DC voltage of $360 \mathrm{~V}$ for electric compressors, performances with electrolytic and film capacitors have been evaluated by experimental tests. Based on extensive experiment evaluations, it is seen that generally, the electric compressor system with the film capacitor based VSI showed better performance in comparison with the electric compressor system of the VSI with the electrolytic capacitor. The electric compressor system with the film capacitor based VSI showed lower power losses and lower peak-to-peak voltage fluctuation, and lower RMS values of DC-link voltage, than that with the electrolytic capacitor based VSI. However, the electric compressor system with the film capacitor exhibited higher percent RMS current value in the DC-link, in comparison with the electrolytic capacitor.

In the next section, when using this VSI, a study on the characteristics of the capacitor according to the type of capacitor attached to the DC link stage will be conducted. Characteristics are \%RMS of current, RMS, loss at the capacitor, heat generation and voltage ripple of the capacitor. Each of these characteristics was analyzed with respect to the current frequency and the magnitude of the current of the inverter for driving the motor. Using experimental data, the results were estimated using MATLAB. 


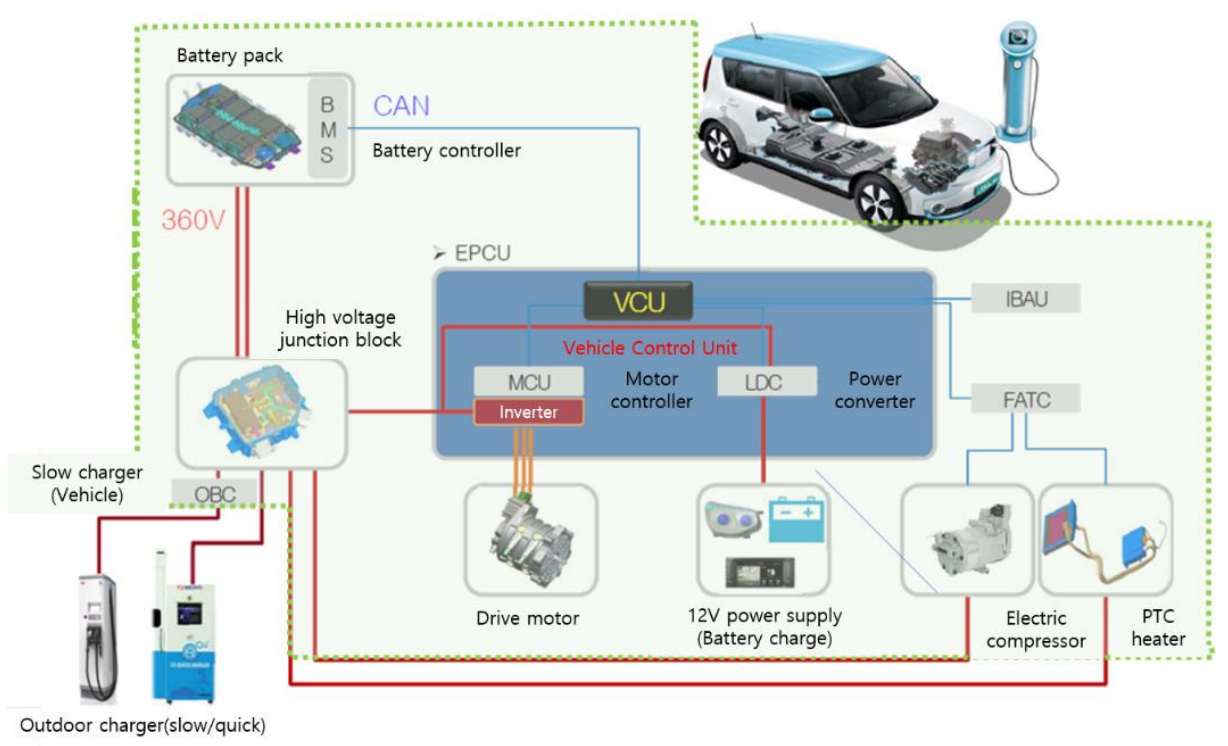

Figure 1. Block diagram of the electric vehicle.

\section{Electric Compressor System Based on Voltage Source Converter in Electric Vehicle}

\subsection{Electric Compressor System}

The HVAC (heating, ventilation and air conditioning) system on the vehicle adjusts the indoor temperature of the vehicle from external heat loads by properly adjusting air temperature, humidity, airflow and cleanliness through refrigerant compression, condensation, expansion and evaporation processes. It plays a role in keeping it in a comfortable state.

In the HVAC system, the compressor serves to make the low temperature/low pressure refrigerant high temperature/high pressure, and accounts for more than $85 \%$ of the HVAC system energy consumption [10]. In the ICE vehicle, the HAVC system uses the low temperature/low pressure refrigerant passing through the evaporator to supply cold air to the driver's seat to create cold air as shown in Figure 2a. It is to provide warm air to the driver's seat $[11,12]$.

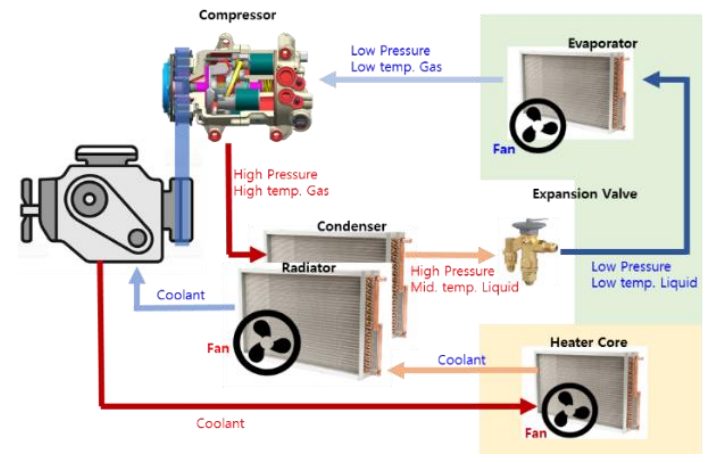

(a)

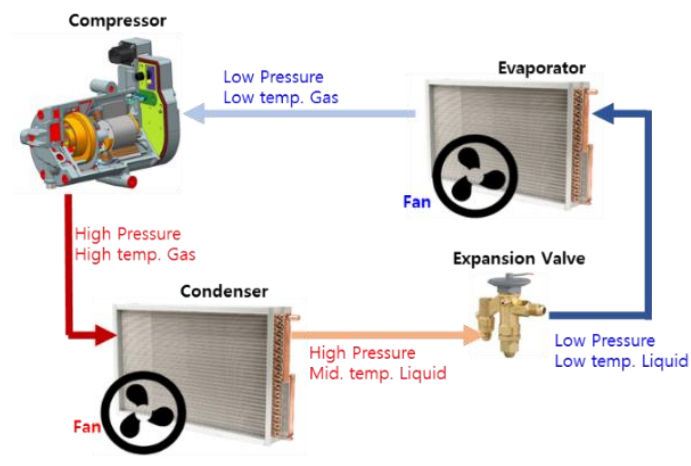

(b)

Figure 2. Diagram of the heating, ventilation and air conditioning (HVAC) system on the vehicle: (a) internal combustion engine (ICE) vehicle and (b) battery electric vehicle (BEV).

However, in heat pump systems that use electric compressors, such as BEV (battery electric vehicle) and FCEV (fuel cell electric vehicle), the system is constructed by combining the low temperature/low pressure refrigerant and high temperature/high pressure refrigerant produced by the electric compressor with hoses and valves of appropriate structures, and cooling air and will supply warm air [13-15]. 
Figure 3 shows the structure of the electric compressor. It is composed of a scroll compression unit for compressing the refrigerant, an electric motor unit for supplying the driving force to the compression unit and an inverter unit for controlling the electric motor at an appropriate speed [16].

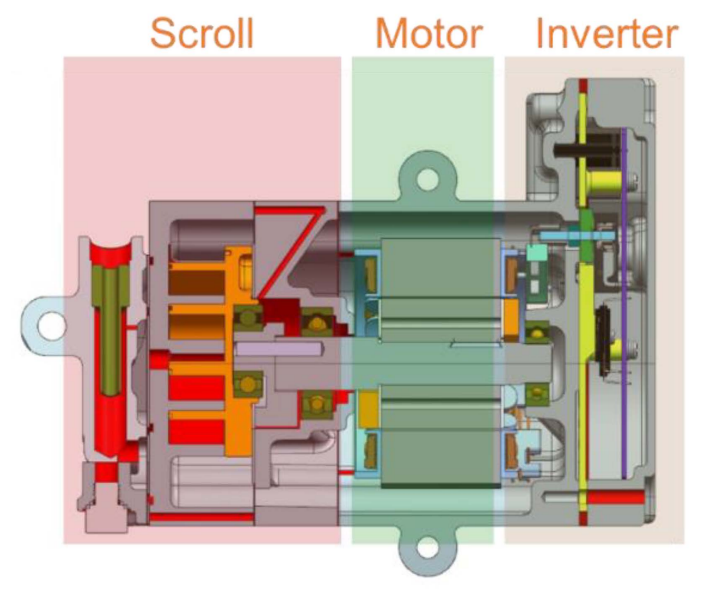

Figure 3. Structure of the electric compressor.

\subsection{Voltage Source Converter in Electric Compressor Systems}

The compressor was the IPM motor and power module that would be described was used for the 3-phase inverter. The DC link voltage was $360 \mathrm{~V}$. The power module used in this experiment was NFVA35065L32 [17]. That module consisted of six IGBT and was composed of a 3-phase bridge. The rated voltage and current were $650 \mathrm{~V}$ and $50 \mathrm{~A}$, respectively. The three-phase VSI for the electric compressor systems operated with the SVM algorithm with the switching frequency of $15 \mathrm{kHz}$. The characteristics of the motor for the compressor had eight poles and the maximum output power of it was $5 \mathrm{~kW}$. As shown in Table 1, the maximum speed of the motor was $8600 \mathrm{rpm}$. The details are described in the Table 1.

Table 1. Properties of interior permanent magnet (IPM) motor.

\begin{tabular}{cc}
\hline Character & Properties \\
\hline Rated Power $(\mathrm{kW})$ & 4.0 \\
Rated Speed (rpm) & 6000 \\
Maximum Speed $(\mathrm{rpm})$ & 8600 \\
Rated Torque $(\mathrm{Nm})$ & 6.3 \\
Poles/Slots & $8 / 12$ \\
Winding method & Concentrated method \\
Type of PM & V-shape \\
Outer diameter of stator $(\mathrm{mm})$ & 94 \\
Outer diameter of rotor $(\mathrm{mm})$ & 48.6 \\
Air gap (mm) & 0.5 \\
Depth of lamination $(\mathrm{mm})$ & 47 \\
Br of PM $(\mathrm{T})$ & 1.39 \\
Resistance per phase $(\Omega)$ & 0.37 \\
\hline
\end{tabular}

Based on what was mentioned, the experimental setup is shown in Figure 4. It is a device to observe the waveform of each part by driving the IPM motor with VSI, an oscilloscope, etc.

Figure 5 shows the motor current waveform when the motor speed was $1000 \mathrm{rpm}$ and the phase current was $10 \mathrm{~A}$. The upper one was the reduced waveform of motor current and the lower one was the enlarged one. Considering that the period of the current was $15 \mathrm{~m} \mathrm{sec}$ and the number of poles of the IPM motor was eight poles, it could be seen that the speed of the motor was $1000 \mathrm{rpm}$ and the current of the motor was a sinusoidal wave through the enlarged waveform. 


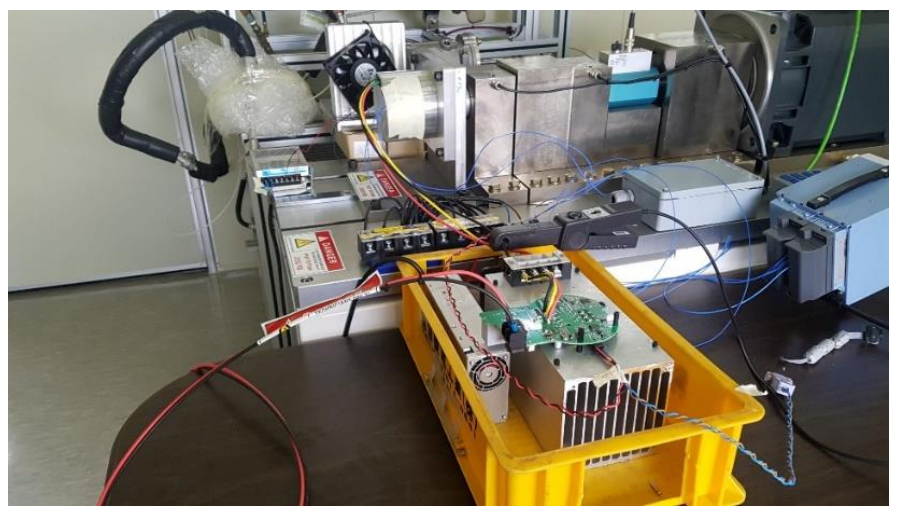

Figure 4. Setup of a voltage source inverter (VSI).

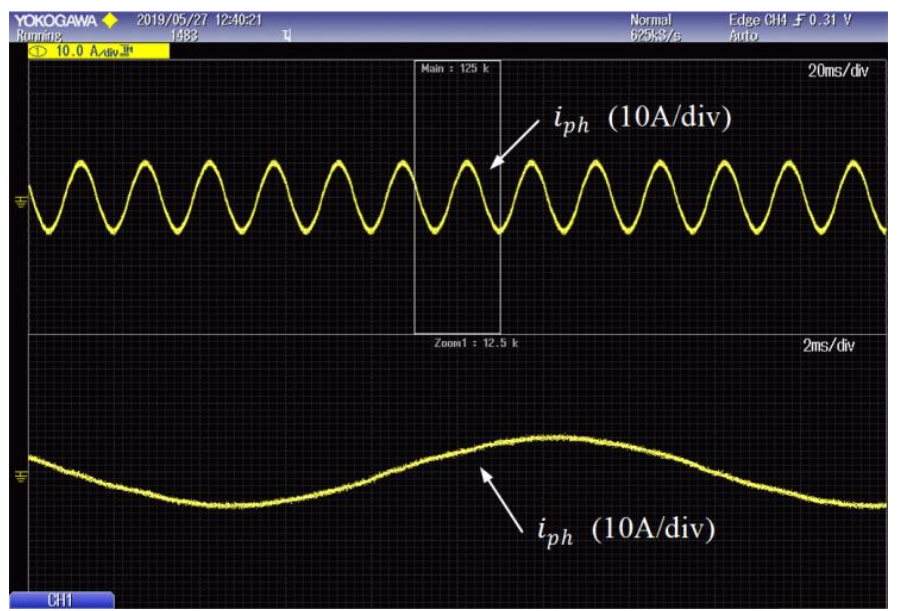

Figure 5. Experimental waveform of the motor current (motor speed $=1000 \mathrm{rpm}$ and motor current $=10 \mathrm{~A}$ ).

Figure 6 shows the waveform of the VSI and motor, the yellow line is the motor current (5 A/div), the cyan line is the line-to-line voltage of VSI ( $5 \mathrm{~V} / \mathrm{div})$, the green line is the capacitor current (10 A/div) and the purple line is the AC component of capacitor voltage (500 V/div). The phase difference of the line-to-line voltage and phase current of the inverter was about 60 degrees. Among the waveforms, the current of the DC link capacitor was to be studied.

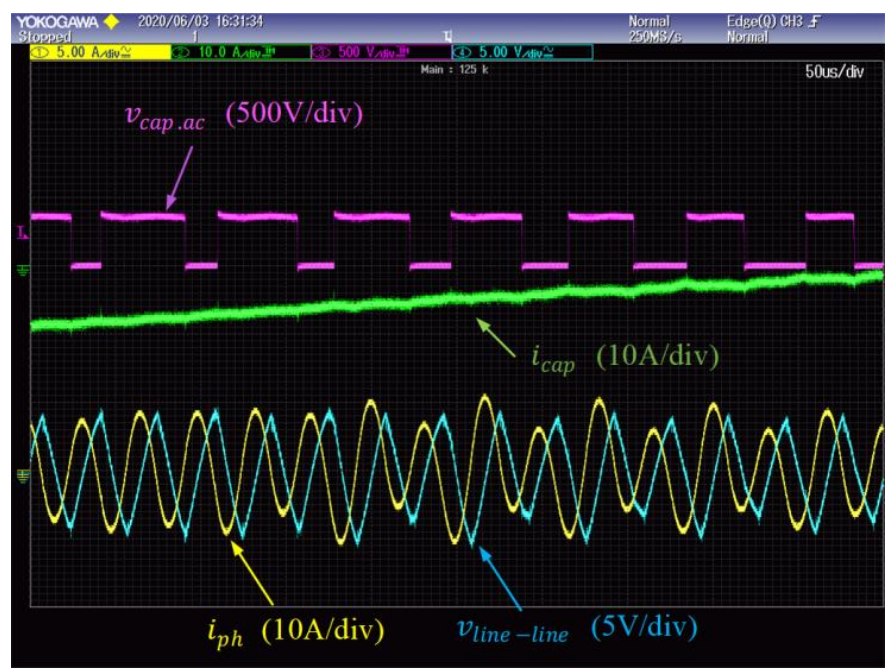

Figure 6. Experimental waveforms of the line-to-line voltage of VSI, motor current, capacitor current and AC component of the capacitor voltage. 


\section{DC Capacitors Used in VSI of the Electric Compressor System in an Electric Vehicle}

\subsection{Electrolytic Capacitor and Film Capacitor}

There are three types of capacitors widely used for the power electronic system, which are aluminum electrolytic capacitors (Al-Caps), metallized polypropylene film capacitors (MPPF-Caps) and high capacitance multilayer ceramic capacitors (MLC-Caps). The performance of capacitors depends on the property of dielectric materials $\left(\mathrm{Al}_{2} \mathrm{O}_{3}\right.$, polypropylene and ceramics), which are used in Al-Caps, MPPF-Caps and MLC-Caps. Figure 7 shows the constructions of Al-Cap in the cylinder shape and cross section. The Al-Cap consists of two aluminum foils, which are parallel plates, the positive foil is the anode and the negative foil is the cathode. The aluminum forms a thin layer of the aluminum oxide $\left(\mathrm{Al}_{2} \mathrm{O}_{3}\right)$ layer by anodic oxidation. A space paper separates the foils to avoid the contact between anode and cathode foils; then, the foils and the space paper are wound together. The electrolyte covers the etched rough structure of the aluminum oxide layer on the anode, serves as the cathode and increases the anode surface. Aluminum tabs are etched to the anode and cathode foils in order to connect the capacitor with the outer circuits.

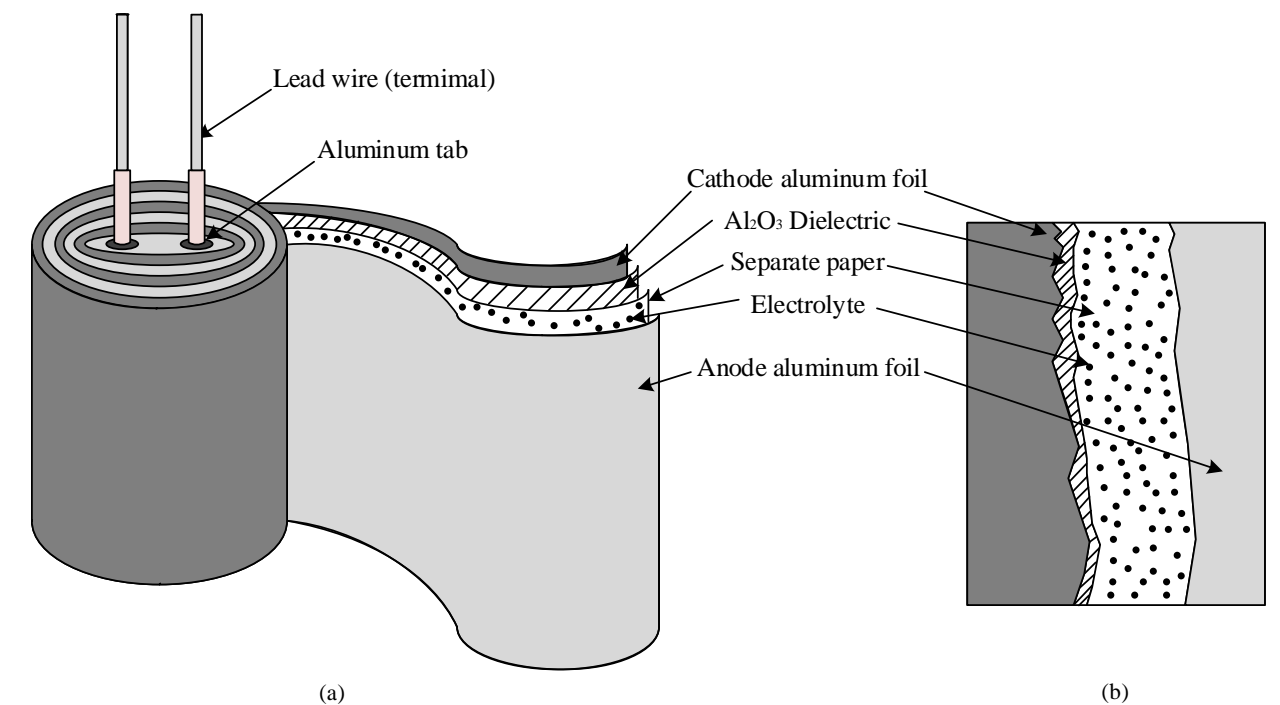

Figure 7. The constructions of the aluminum electrolytic capacitor (Al-Cap): (a) the cylinder construction and (b) the cross section of the cylinder shape.

Figure 8 presents the typical construction and the cross section of the cylindrical MPPF-Cap. The construction of the MPPF-Cap contains two pieces of polypropylene film, which are wound into a cylindrical shape on an insulating mandrel. Each strip has a very thin metallization layer, usually aluminum, that is applied to one or both sides to serve as electrodes. The capacitor is wound so that there are the clear margins at each ends of the cylinder. A key advantage of this construction is that the direct contact between the electrodes and both ends of the cylinder are provided and keep the current path through the electrodes shortly, thus the internal losses is low.

\subsection{Capacitor Characteristics}

Figure 9 shows the frequency characteristics of ESR values of the electrolytic and film capacitors. The ESR value of the film capacitor $(10 \mu \mathrm{F})$ was lower than that of the four parallel connected electrolytic capacitors $(88 \mu \mathrm{F})$ in the entire frequency ranges. The film capacitor ESR increased with increasing frequency. On the other hand, the ESR values of the electrolytic capacitors reduced with the increase of frequency. Dependency of film capacitor ESR on frequency was low in comparison with that of the electrolytic capacitor ESR. 


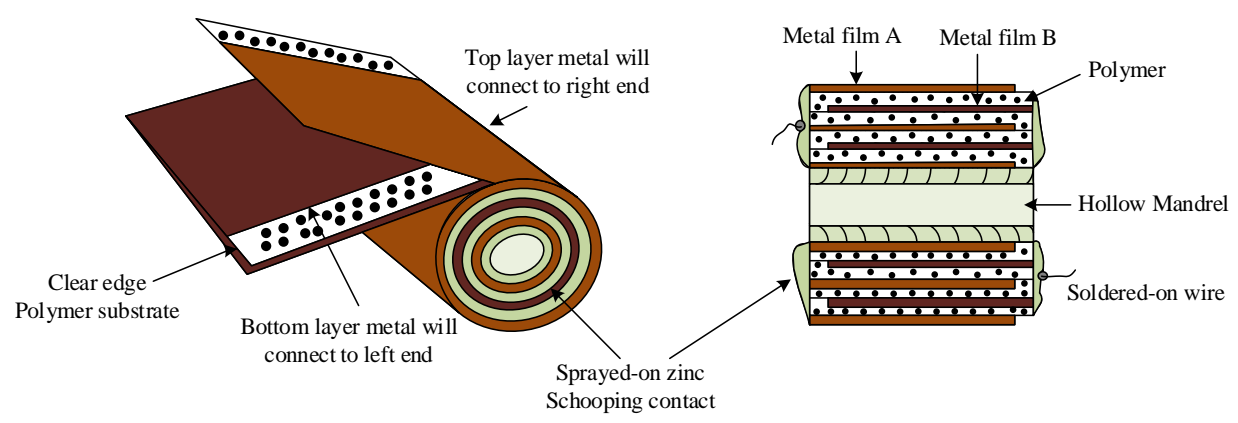

(a)

(b)

Figure 8. The constructions of the metallized polypropylene film capacitor (MPPF-Cap): (a) the cylinder construction and (b) the cross section of the cylinder shape.

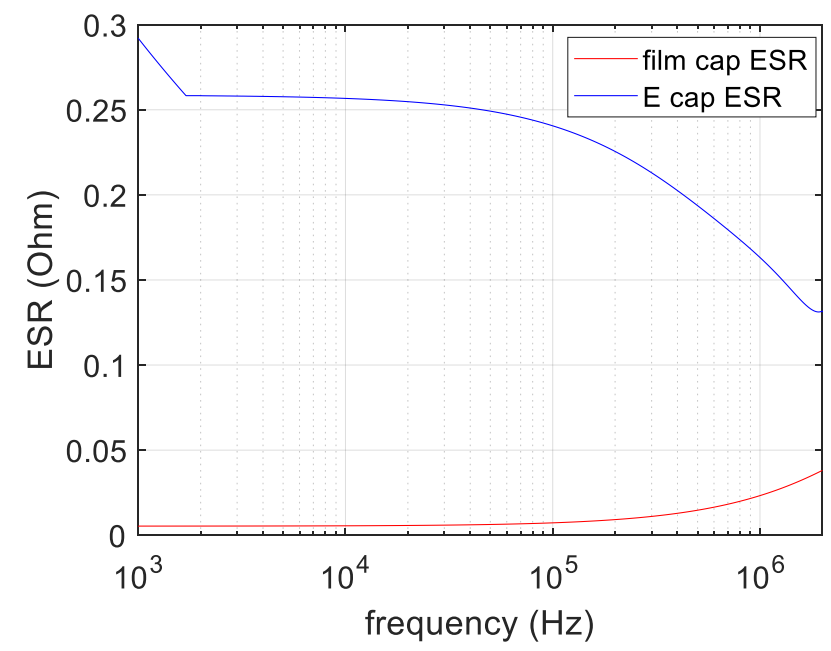

Figure 9. Frequency characteristics of ESR values of the electrolytic and film capacitors used in DC capacitor of VSI in electric compressor systems.

Figure 10 shows the frequency characteristics of capacitance values of the electrolytic and film capacitors. The capacitance value of the film capacitor $(10 \mu \mathrm{F})$ slightly increased with increasing frequency. On contrast, the capacitance value of electrolytic capacitor $(88 \mu \mathrm{F})$ significantly reduced with increasing frequency. The variation of the film capacitor capacitance on frequency was negligible in comparison with that of the electrolytic capacitor capacitance.

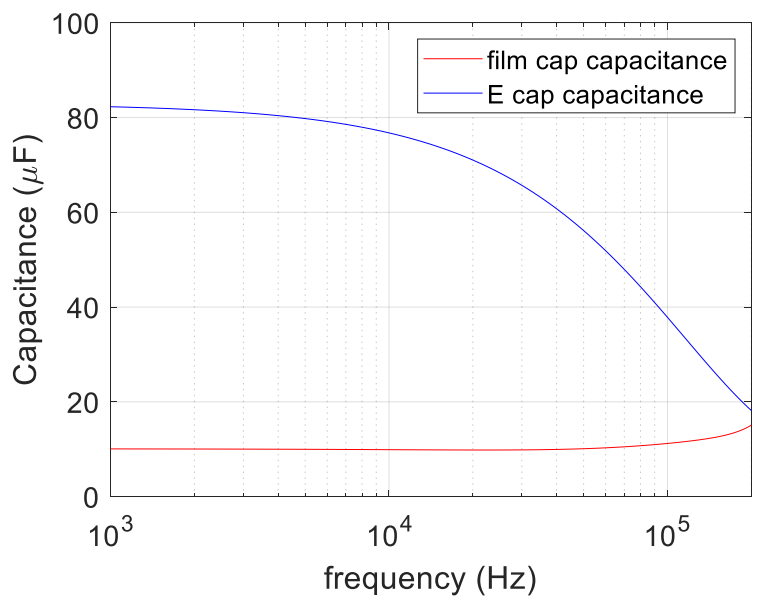

Figure 10. Frequency characteristics of capacitance values of the electrolytic and film capacitors used in the DC capacitor of VSI in electric compressor systems. 
Figure 11 shows the frequency characteristics of impedance values of the electrolytic and film capacitors. The impedance value of film capacitor $(10 \mu \mathrm{F})$ slightly increased with increasing frequency. On the contrary, the impedance value of electrolytic capacitor $(88 \mu \mathrm{F})$ significantly reduced with increasing frequency. It shows the difference of film capacitor impedance was insignificant.

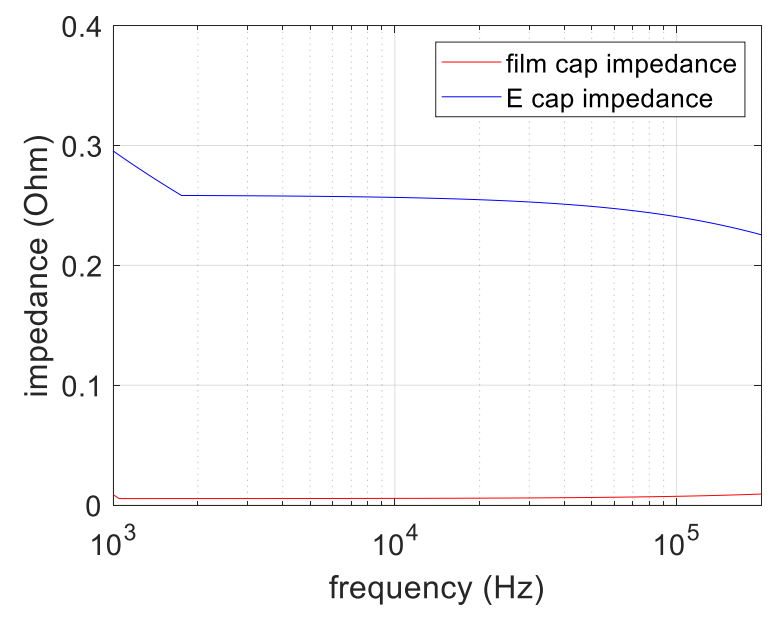

Figure 11. Frequency characteristics of impedance values of the electrolytic and film capacitors used in the DC capacitor of VSI in electric compressor systems.

\subsection{Characteristics of DC-Link Voltages and Currents of Two Capacitors Used in Electric Compressor Systems}

Figure 12 shows frequency responses of the DC-link currents of the VSI with the electrolytic and film capacitors, which magnitudes were depicted in ampere. It is seen at Figure 12a that the magnitudes of the DC-link currents with the film capacitors were slightly higher than those with the electrolytic capacitors at Figure 12b, due to a much smaller capacitance. In addition, it can be noted that the magnitude differences between the DC-link currents with the two types of capacitors become smaller in higher frequency regions, as shown in Figure 12a,b. Furthermore, magnitude variations of the DC-link currents are less dependent on frequency, in a case of the film capacitors, as shown in expanded figures inside circles in Figure 12. Especially, in areas of low frequency, the DC-link current magnitude obtained by the film capacitor is less affected by frequency changes, which leads to reduced magnitude ripples in the frequency response of the DC-link current as it is shown at Figure 12a.

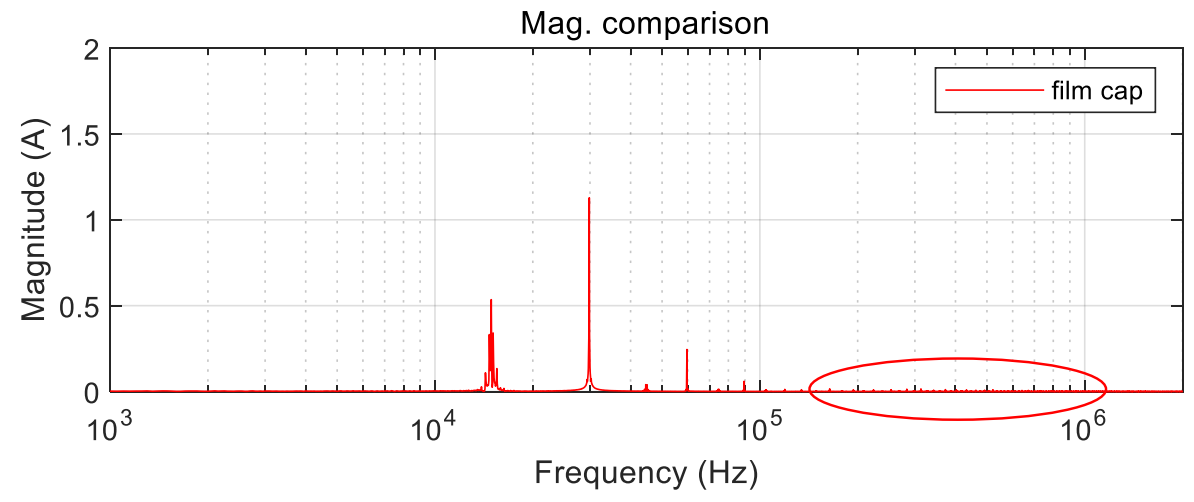

(a)

Figure 12. Cont. 


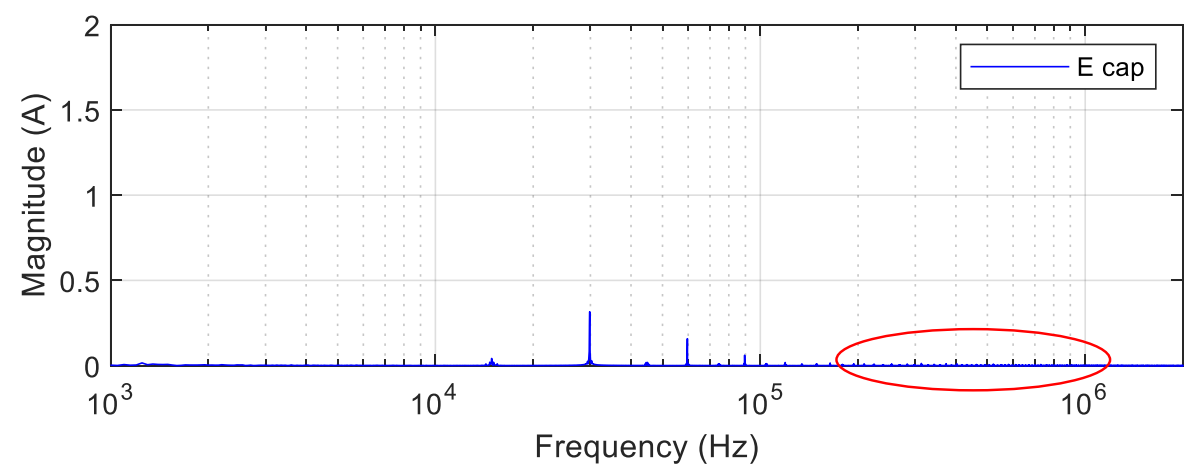

(b)

Figure 12. Magnitude of DC-link currents of VSI with electrolytic and film capacitors as functions of frequency. (a) electrolytic and (b) film capacitors as functions of frequency.

From Figures 13 and 14, it could be seen that the higher the motor speed gets, the larger the magnitude at the switching frequency $\mathrm{f}_{\mathrm{sw}}$ and $2 \mathrm{f}_{\mathrm{sw}}$. Additionally, for the electrolytic capacitor current, switching the frequency component was smaller than the component at $2 \mathrm{f}_{\mathrm{sw}}$. For the driving motor, the major current components could be located at $\mathrm{f}_{\mathrm{sw}}$ and $2 \mathrm{f}_{\mathrm{sw}}$ [18].

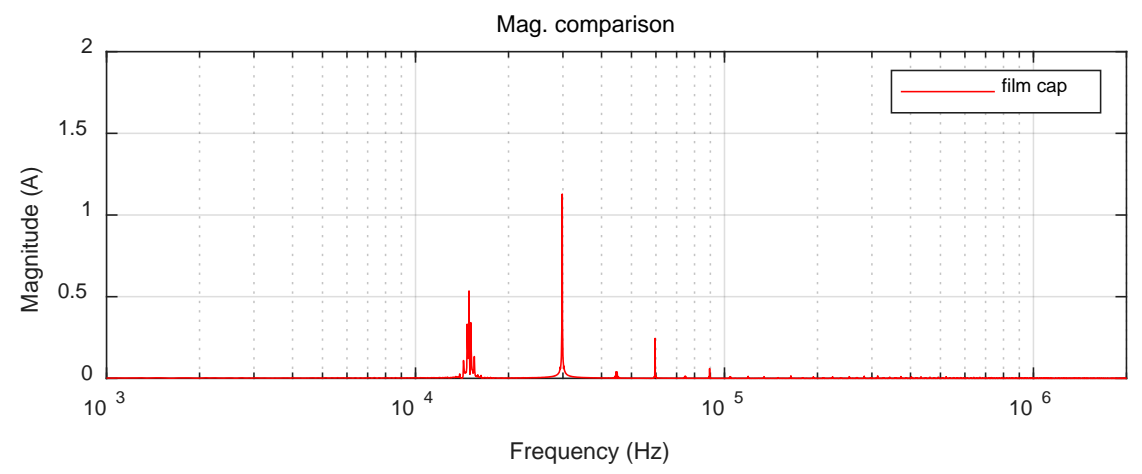

(a)

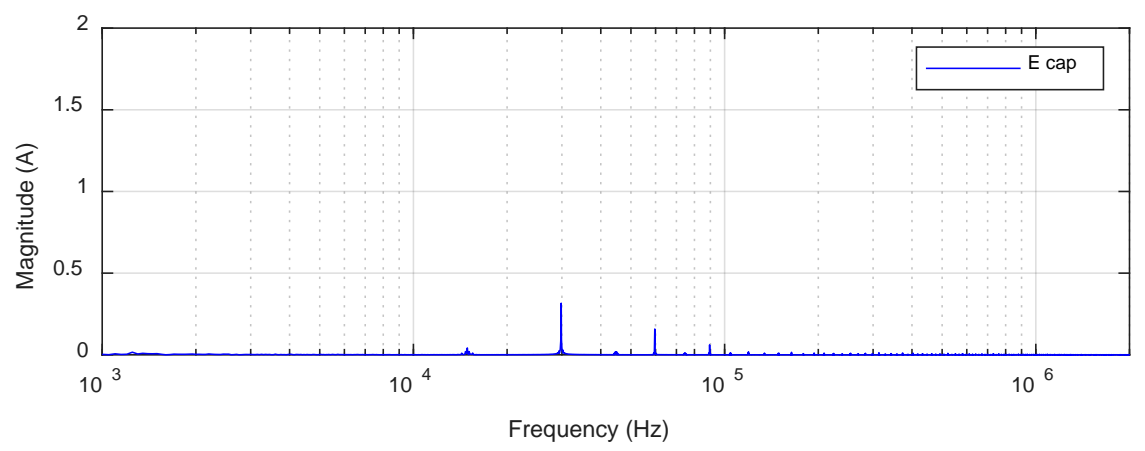

(b)

Figure 13. Magnitude of DC-link currents of VSI with film (a) and electrolytic (b) capacitors as functions of frequency. At motor speed $=1000 \mathrm{rpm}$ and phase current amplitude $=20 \mathrm{~A}$.

The percent RMS DC-link current is defined by the total RMS values of all AC components divided by the DC component as

$$
I_{r m s . p e r}=\frac{\sqrt{\sum I_{a c}\left(f_{i}\right)^{2}}}{I_{d c}} \times 100 \%
$$


where, the AC components values were considered until 6.25 (MHz). Figure 15 shows the percent RMS DC-link current in (1) the electrolytic capacitor and the film capacitor as functions of the motor speed and motor current of the electric compressor system. In all regions presented, the current percent RMS of the film capacitor was greater than that of the electrolytic capacitor. In Equation (1), $I_{a c}\left(f_{i}\right)$ is the magnitude of the current according to frequency $f_{i}$, and $I_{d c}$ is the dc component.

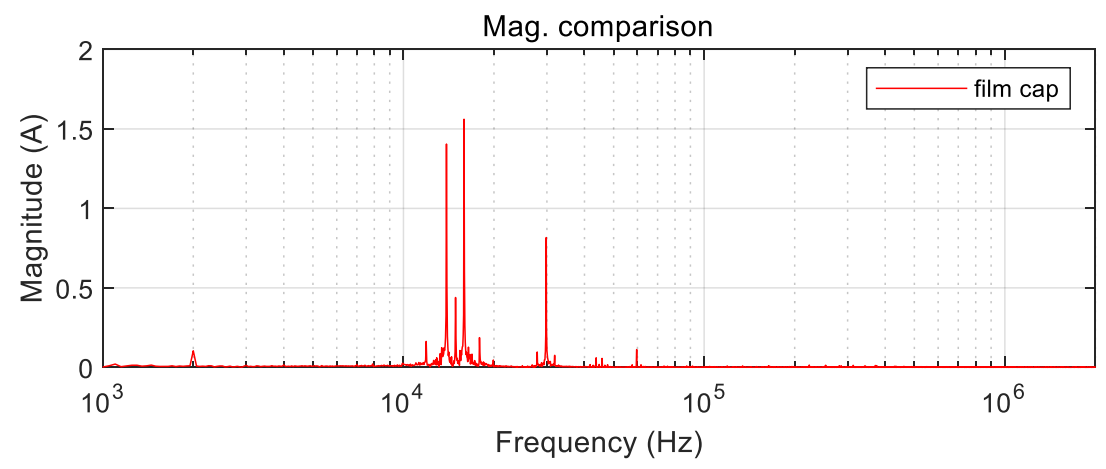

(a)

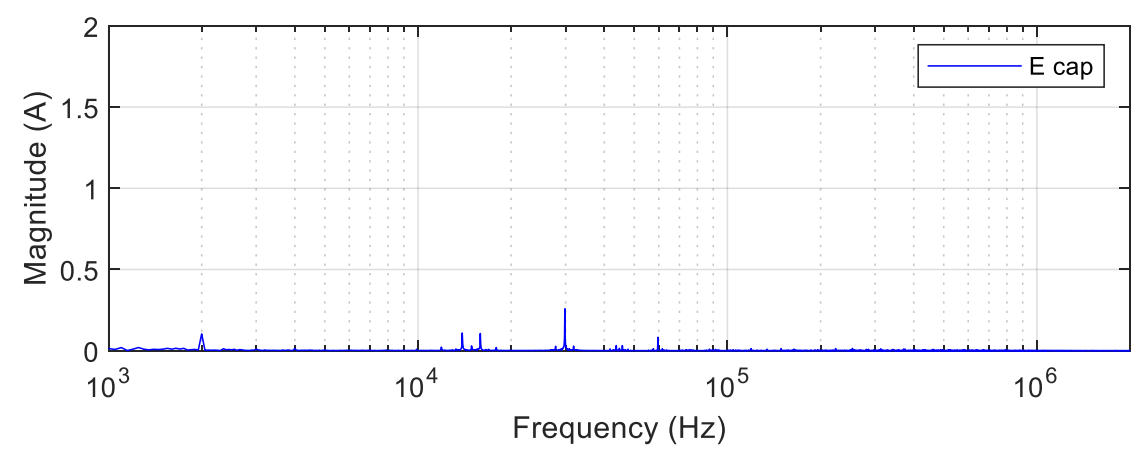

(b)

Figure 14. Magnitude of DC-link currents of VSI with film (a) and electrolytic (b) capacitors as functions of frequency. At motor speed $=5000 \mathrm{rpm}$ and phase current amplitude $=10 \mathrm{~A}$.

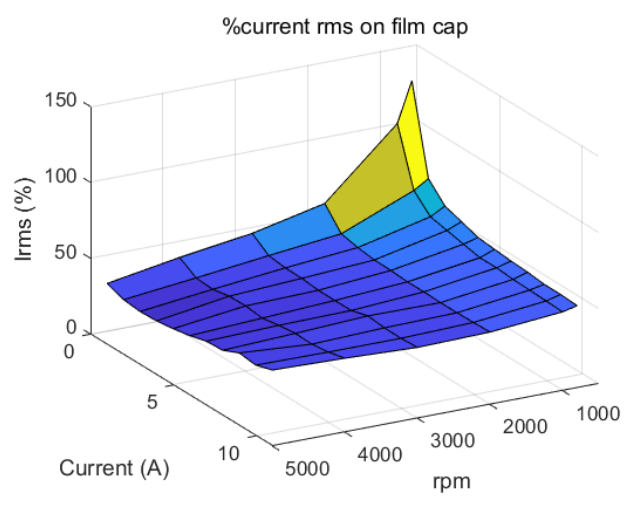

(a)

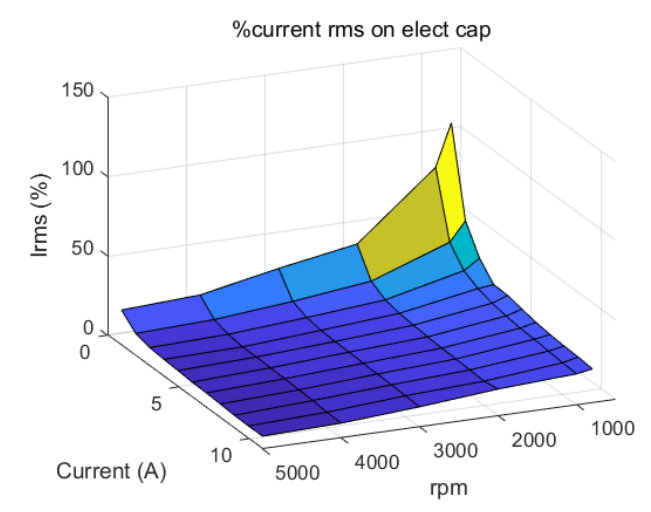

(b)

Figure 15. Percent RMS of DC-link currents of VSI with electrolytic (a) and film (b) capacitors as functions of speed and motor current.

The reason why the current percent RMS value for both capacitors is higher than the other regions in the low-speed and low-current regions is that the DC current value in the region is much smaller than 1. 
Figure 16 shows the percent RMS DC-link current values obtained by the VSI with electrolytic and film capacitors as functions of motor currents, which were calculated by (1). Figure 16 shows that the RMS currents of the DC-link currents with the film capacitor based VSI were higher than those by the VSI with the electrolytic capacitor in all motor current values of the electric compressors, due to a much lower capacitance value, which was about 10 times lower than that of the electrolytic capacitor. The increased RMS current values of the film capacitor could lead to the increased losses of the battery.

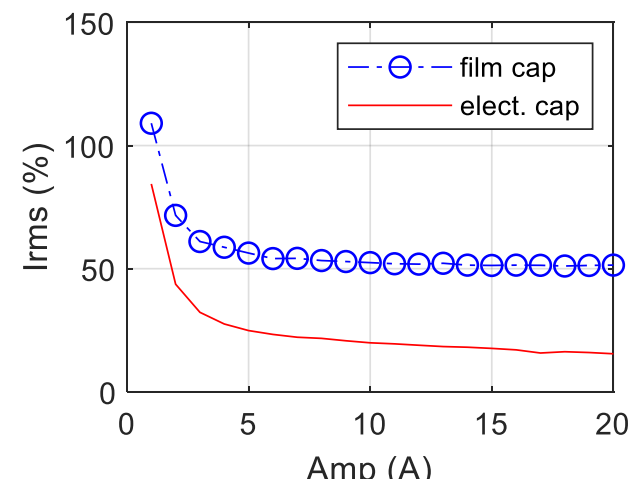

(a) motor speed $=1000(\mathrm{rpm})$

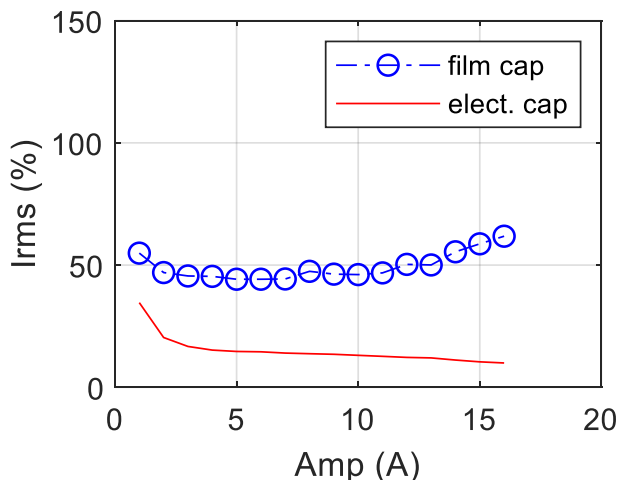

(c) motor speed $=3000(\mathrm{rpm})$

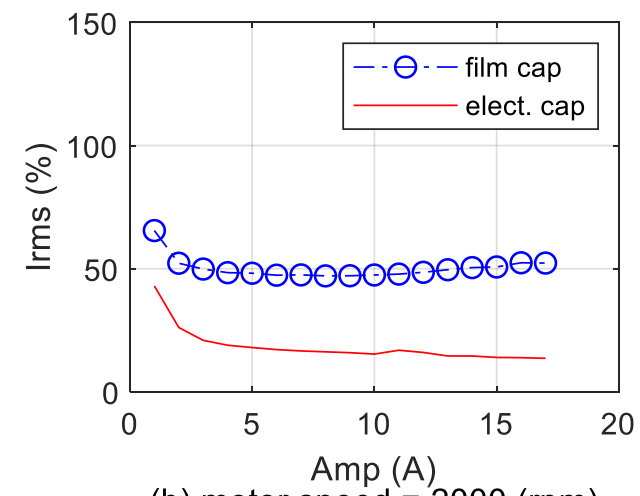

(b) motor speed $=2000(\mathrm{rpm})$

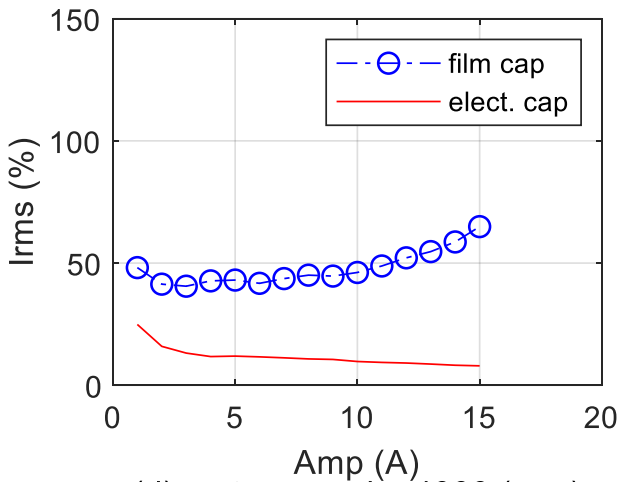

(d) motor speed $=4000(\mathrm{rpm})$

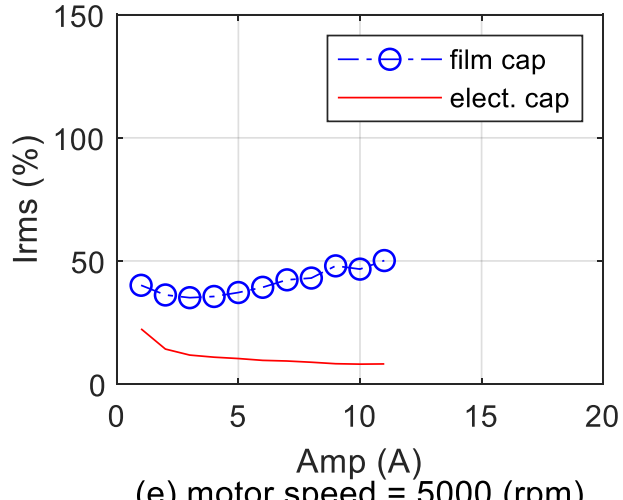

Figure 16. Percent RMS DC-link current values obtained by the VSI with electrolytic and film capacitors as functions of motor currents.

Figure 17 shows the percent RMS DC-link current values obtained by the VSI with electrolytic and film capacitors versus the motor speed. It is seen that the RMS currents of the DC-link currents with the film capacitor based VSI were higher than those by the VSI with the electrolytic capacitor in all operating speed ranges of the IPM in the electric compressors. It is because the capacitance of the film capacitor was about 10 times lower than that of the electrolytic capacitor. 


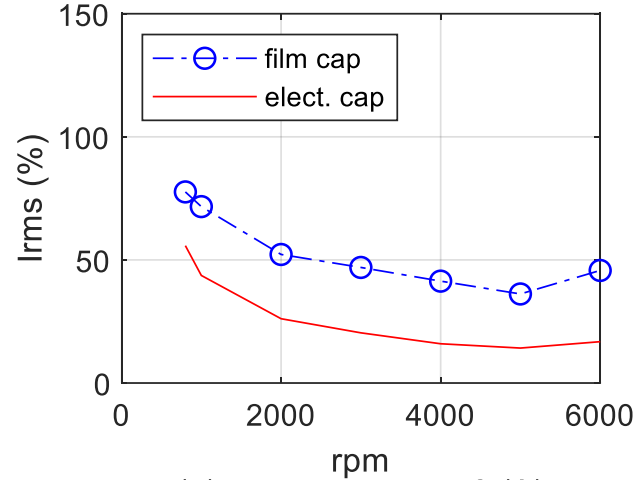

(a) motor current $=2(\mathrm{~A})$

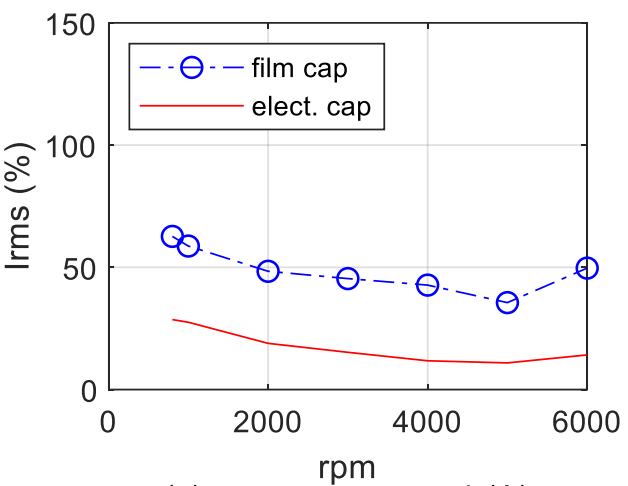

(c) motor current $=4(\mathrm{~A})$

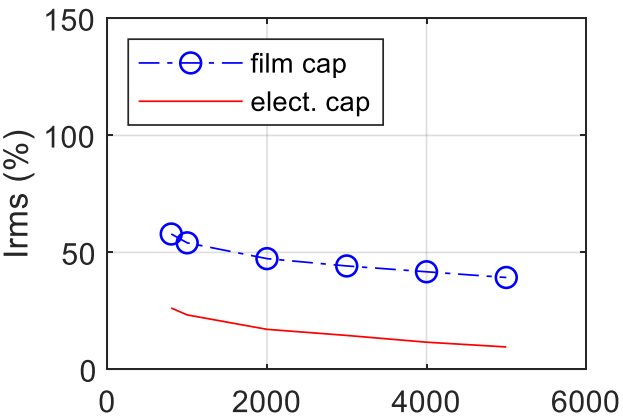

(e) motor current $=6(\mathrm{~A})$

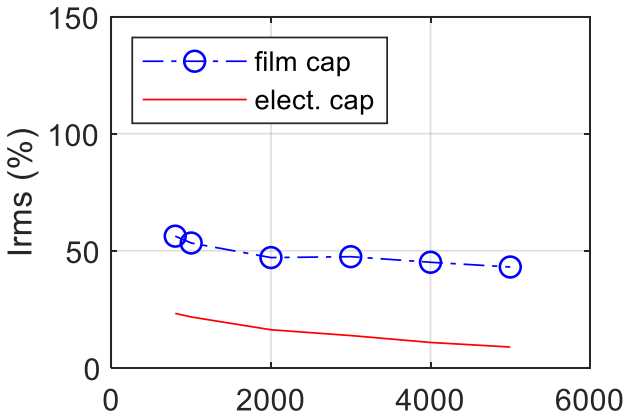

(g) motor current $=8(A)$

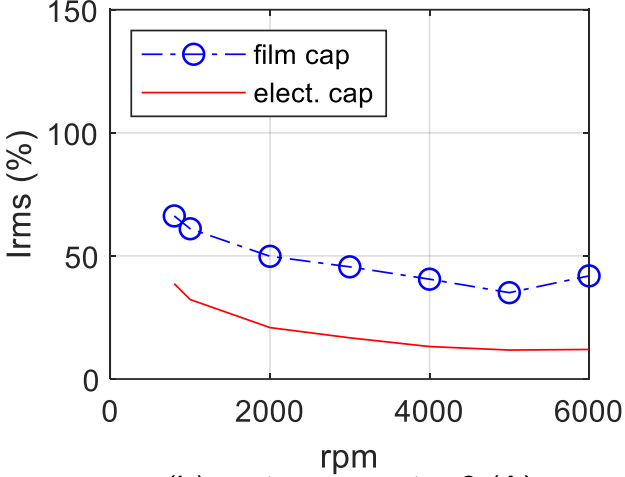

(b) motor current $=3(\mathrm{~A})$

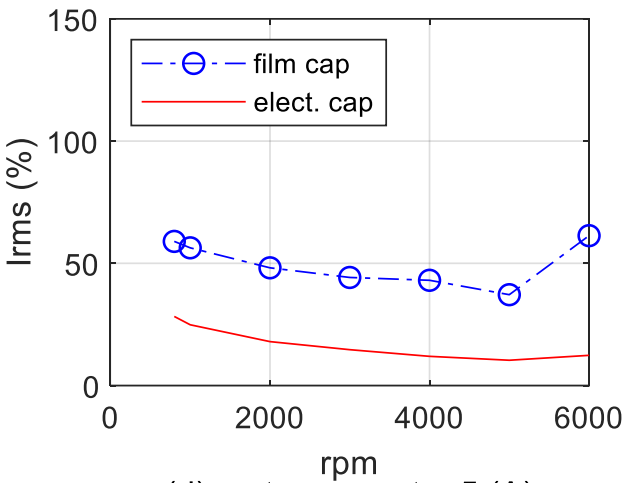

(d) motor current $=5(A)$

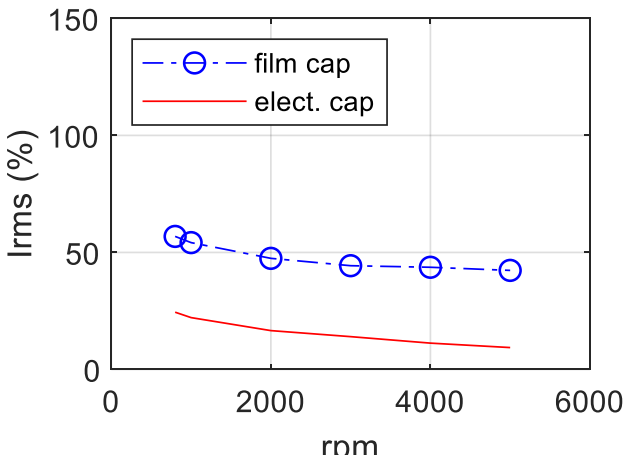

(f) motor current $=7(\mathrm{~A})$

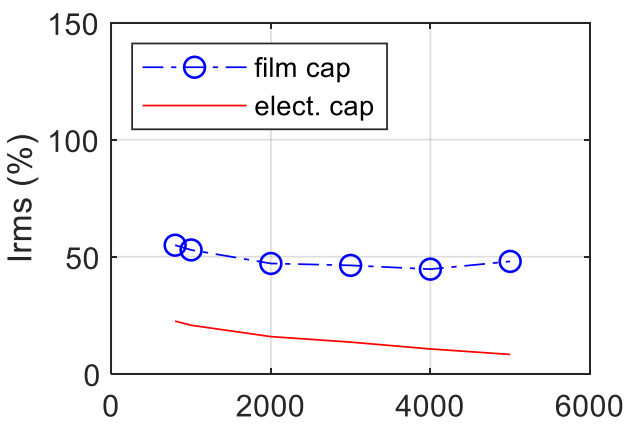

(h) motor current $=9(A)$

Figure 17. Cont. 

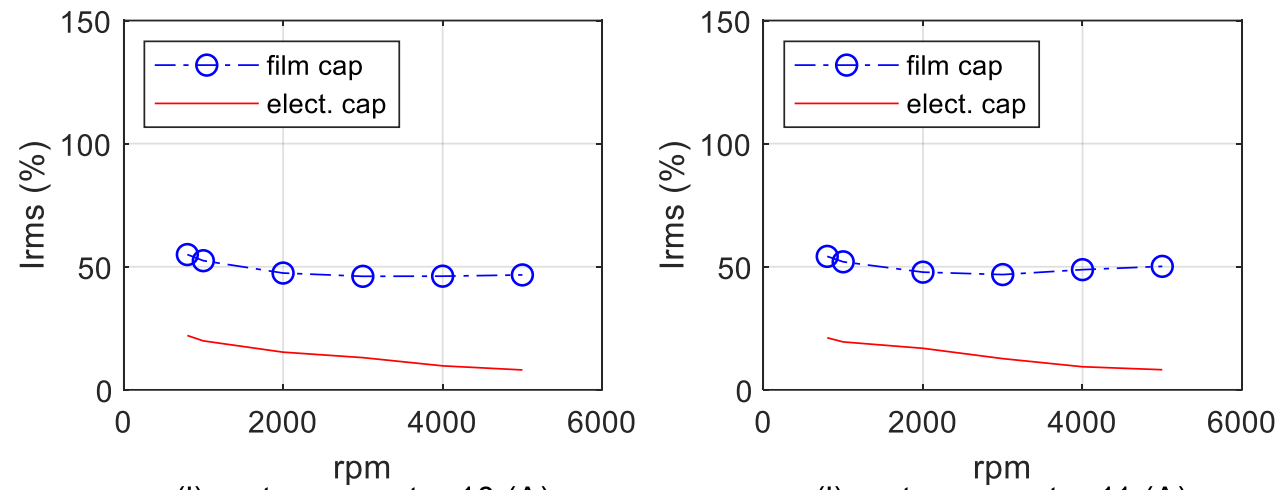

(i) motor current $=10(\mathrm{~A})$

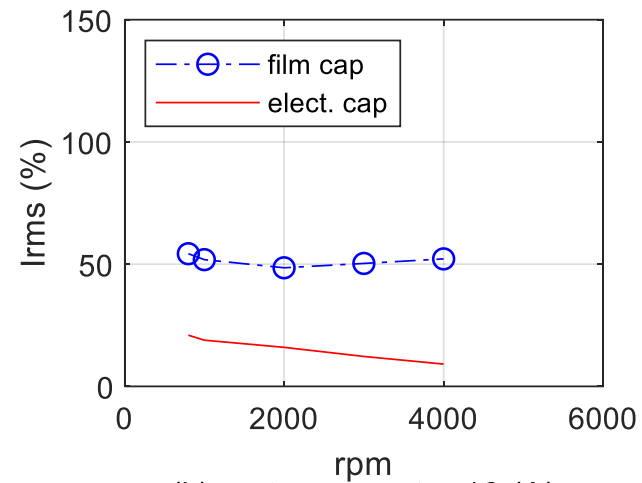

(j) motor current $=11(\mathrm{~A})$

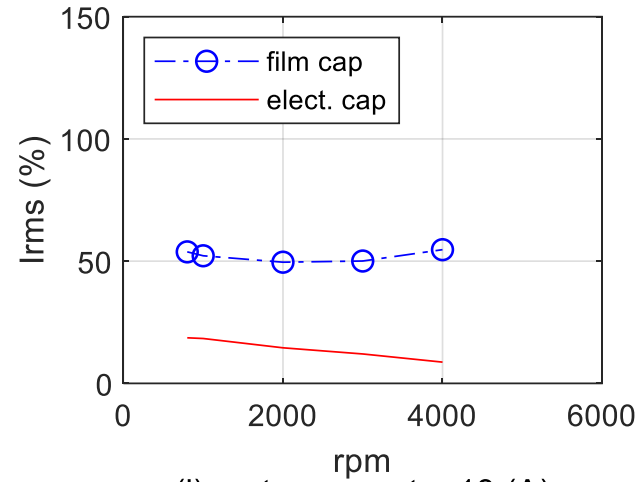

(k) motor current $=12(\mathrm{~A})$

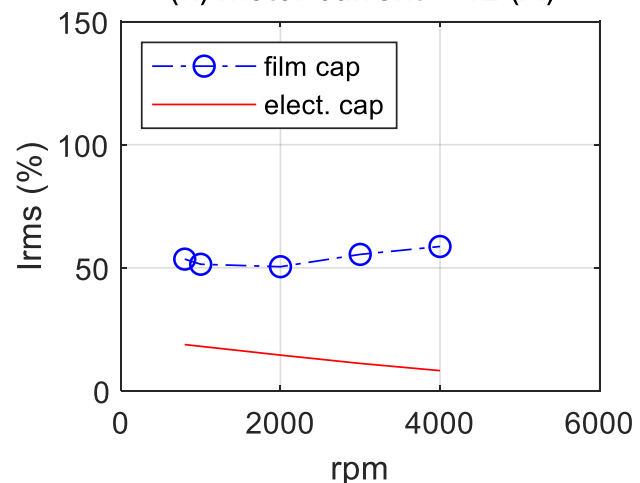

(I) motor current $=13(\mathrm{~A})$

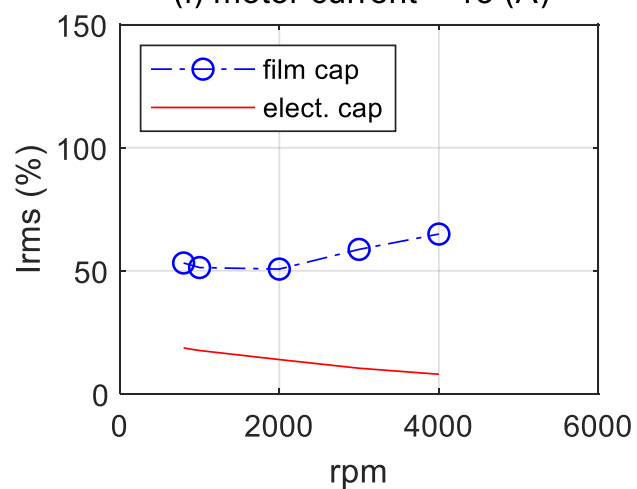

(m) motor current $=14(\mathrm{~A})$

(n) motor current $=15(\mathrm{~A})$
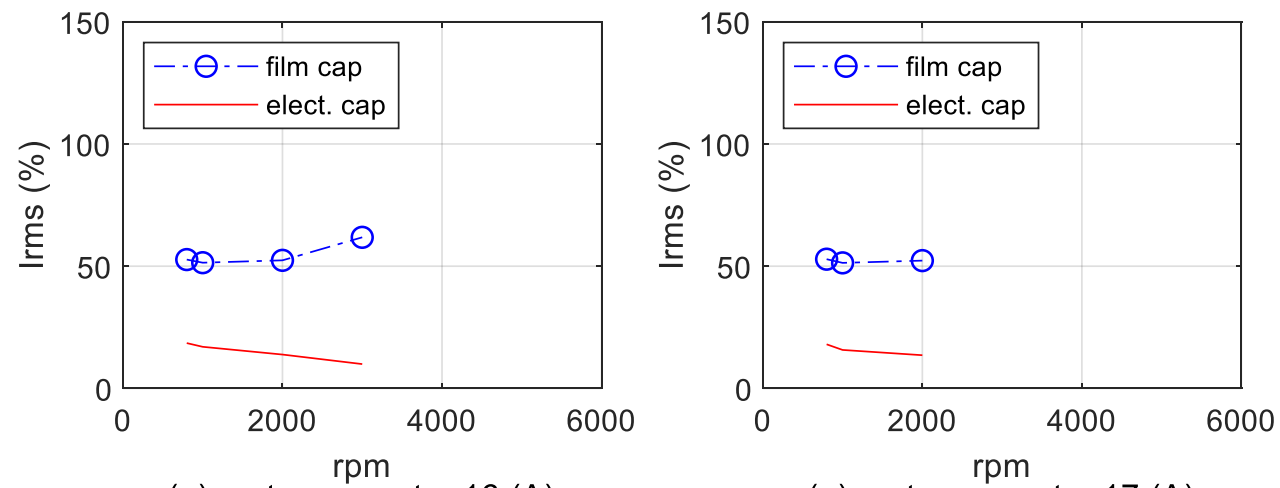

(o) motor current $=16(\mathrm{~A})$

(p) motor current $=17(\mathrm{~A})$

Figure 17. Cont. 


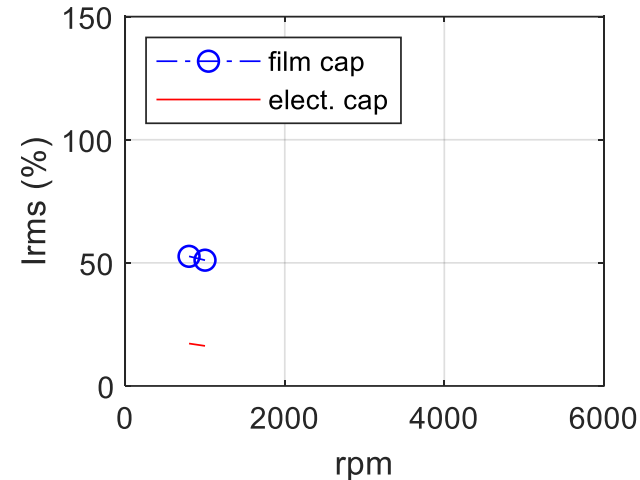

(q) motor current $=18(\mathrm{~A})$

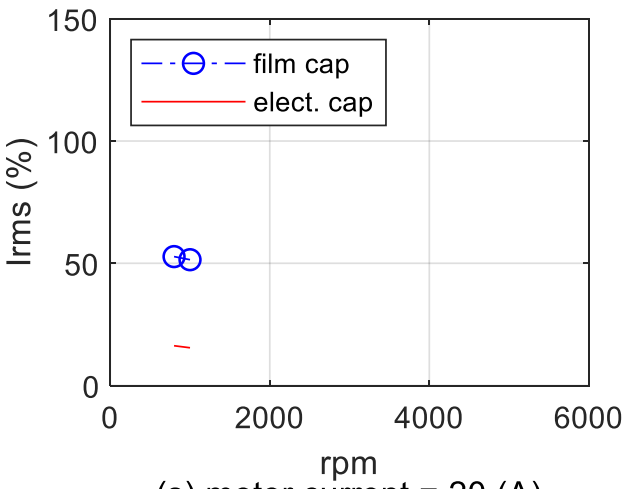

(s) motor current $=20(\mathrm{~A})$

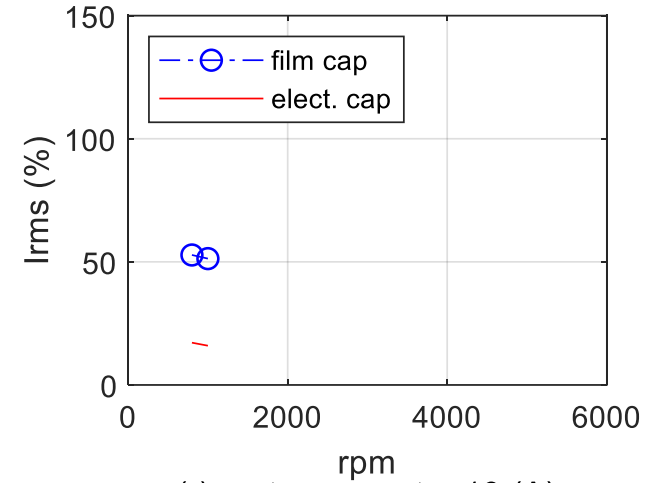

(r) motor current $=19(\mathrm{~A})$

Figure 17. Percent RMS DC-link current obtained by the VSI with electrolytic and film capacitors versus motor speed.

Tables 2 and 3 are a summary of Figures 16 and 17 into a table. As mentioned earlier, the current percent RMS in the film capacitor was larger.

Table 2. Percent RMS DC-link current obtained by the VSI with electrolytic and film capacitor at an rpm range of 800-2000.

\begin{tabular}{ccccccc}
\hline Speed (rpm) & \multicolumn{2}{c}{$\mathbf{8 0 0}$} & \multicolumn{2}{c}{$\mathbf{1 0 0 0}$} & \multicolumn{2}{c}{ 2000 } \\
\hline Current (A) & Film (\%) & Elect (\%) & Film (\%) & Elect (\%) & Film (\%) & Elect (\%) \\
\hline 1 & 135.46 & 110.96 & 109.07 & 84.42 & 65.48 & 43.02 \\
2 & 77.62 & 55.79 & 71.65 & 43.69 & 52.21 & 26.12 \\
3 & 66.24 & 38.72 & 61.02 & 32.27 & 49.85 & 20.89 \\
4 & 62.65 & 28.62 & 58.70 & 27.53 & 48.38 & 18.91 \\
5 & 58.97 & 28.27 & 56.34 & 24.86 & 48.16 & 17.98 \\
6 & 57.87 & 26.24 & 54.10 & 23.30 & 47.35 & 17.14 \\
7 & 56.84 & 24.45 & 54.19 & 22.15 & 47.47 & 16.59 \\
8 & 56.22 & 23.22 & 53.30 & 21.70 & 47.07 & 16.23 \\
9 & 54.93 & 22.50 & 52.90 & 20.72 & 47.12 & 15.87 \\
10 & 54.95 & 22.07 & 52.45 & 19.89 & 47.44 & 15.31 \\
11 & 54.21 & 21.14 & 52.00 & 19.46 & 47.81 & 16.87 \\
12 & 54.27 & 20.95 & 51.84 & 18.91 & 48.52 & 15.97 \\
13 & 53.80 & 18.65 & 52.20 & 18.36 & 49.57 & 14.55 \\
14 & 53.52 & 18.82 & 51.43 & 18.10 & 50.44 & 14.53 \\
15 & 53.17 & 18.65 & 51.31 & 17.62 & 50.69 & 13.94 \\
16 & 52.71 & 18.55 & 51.44 & 17.03 & 52.40 & 13.86 \\
17 & 52.87 & 18.05 & 51.36 & 15.75 & 52.28 & 13.59 \\
18 & 52.64 & 17.22 & 51.08 & 16.27 & N/A & N/A \\
19 & 52.79 & 17.17 & 51.31 & 15.95 & N/A & N/A \\
20 & 52.73 & 16.27 & 51.46 & 15.44 & N/A & N/A \\
\hline
\end{tabular}


Table 3. Percent RMS DC-link current obtained by the VSI with electrolytic and film capacitor at an rpm range of 3000-6000.

\begin{tabular}{ccccccccc}
\hline Speed (rpm) & \multicolumn{2}{c}{3000} & \multicolumn{2}{c}{4000} & \multicolumn{2}{c}{5000} & \multicolumn{2}{c}{6000} \\
\hline Current (A) & Film (\%) & Elect (\%) & Film (\%) & Elect (\%) & Film (\%) & Elect (\%) & Film (\%) & Elect (\%) \\
\hline 1 & 54.90 & 34.64 & 48.15 & 24.90 & 40.10 & 22.41 & 161.07 & 37.82 \\
2 & 46.94 & 20.38 & 41.38 & 15.94 & 36.17 & 14.20 & 45.72 & 16.78 \\
3 & 45.56 & 16.73 & 40.55 & 13.19 & 35.07 & 11.76 & 41.89 & 12.00 \\
4 & 45.39 & 15.23 & 42.73 & 11.77 & 35.56 & 10.91 & 49.68 & 14.16 \\
5 & 44.22 & 14.67 & 43.06 & 11.95 & 37.17 & 10.35 & 61.32 & 12.36 \\
6 & 44.22 & 14.53 & 41.73 & 11.64 & 39.29 & 9.61 & N/A & N/A \\
7 & 44.33 & 14.01 & 43.66 & 11.25 & 42.32 & 9.35 & N/A & N/A \\
8 & 47.45 & 13.75 & 45.07 & 10.81 & 43.04 & 8.85 & N/A & N/A \\
9 & 46.30 & 13.51 & 44.69 & 10.59 & 48.00 & 8.25 & N/A & N/A \\
10 & 46.11 & 13.09 & 46.17 & 9.75 & 46.67 & 8.08 & N/A & N/A \\
11 & 46.81 & 12.68 & 48.82 & 9.38 & 50.15 & 8.16 & N/A & N/A \\
12 & 50.30 & 12.24 & 52.15 & 9.12 & N/A & N/A & N/A & N/A \\
13 & 50.06 & 12.04 & 54.70 & 8.70 & N/A & N/A & N/A & N/A \\
14 & 55.44 & 11.16 & 58.65 & 8.22 & N/A & N/A & N/A & N/A \\
15 & 58.70 & 10.43 & 64.91 & 7.98 & N/A & N/A & N/A & N/A \\
16 & 61.82 & 9.96 & N/A & N/A & N/A & N/A & N/A & N/A \\
17 & N/A & N/A & N/A & N/A & N/A & N/A & N/A & N/A \\
18 & N/A & N/A & N/A & N/A & N/A & N/A & N/A & N/A \\
19 & N/A & N/A & N/A & N/A & N/A & N/A & N/A & N/A \\
20 & N/A & N/A & N/A & N/A & N/A & N/A & N/A & N/A \\
\hline
\end{tabular}

Figure 18 shows the change of current in the frequency domain as the motor current increased at the same speed. In the case of the film capacitor, Figure $18 \mathrm{a}, \mathrm{c}, \mathrm{e}, \mathrm{g}$, the main component of the current occurred at the switching frequency $\mathrm{f}_{\mathrm{sw}}, 2 \mathrm{f}_{\mathrm{sw}}$, and in the case of the electrolytic capacitor, Figure $18 b, d, f, h$, the main component appeared in the $2 f_{s w}$. This caused the loss of the film capacitor in a certain section to be greater than the loss in the electrolytic capacitor.

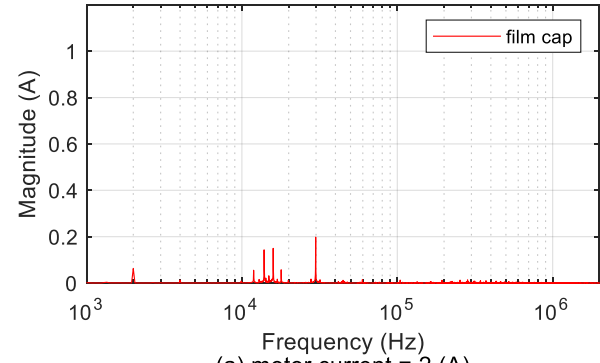

(a) motor current $=2(\mathrm{~A})$

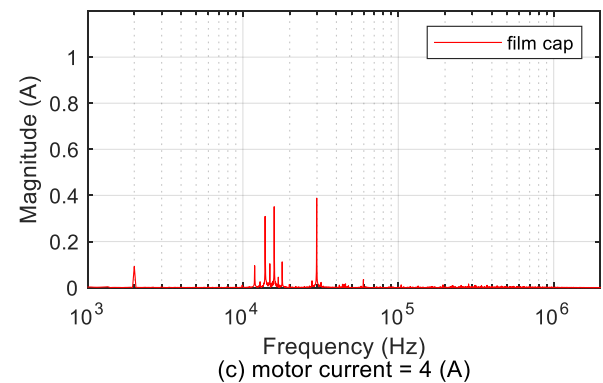

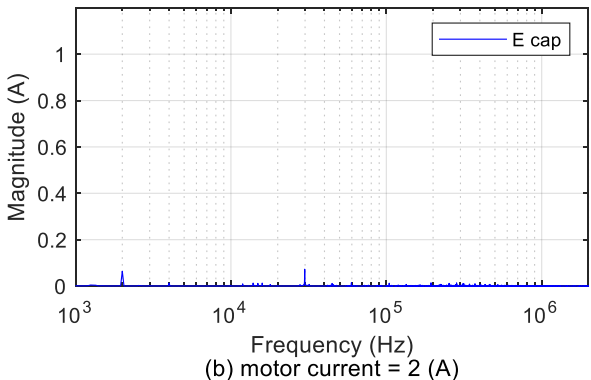

(b) motor current $=2(\mathrm{~A})$

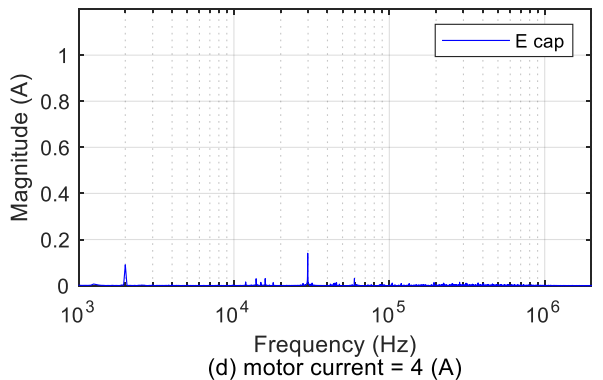

Figure 18. Cont. 


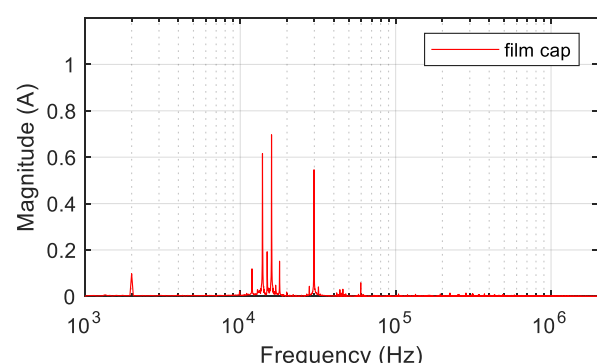

(e) motor current $=6(\mathrm{~A})$

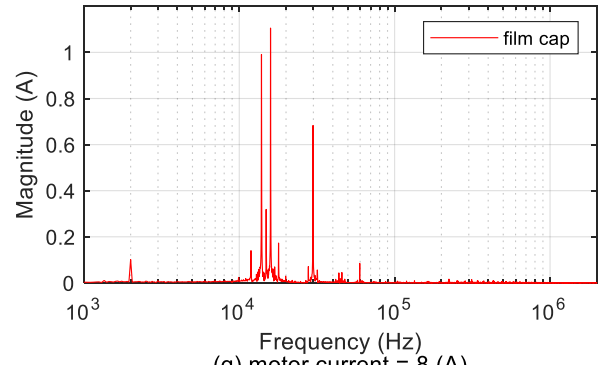

(g) motor current $=8(\mathrm{~A})$

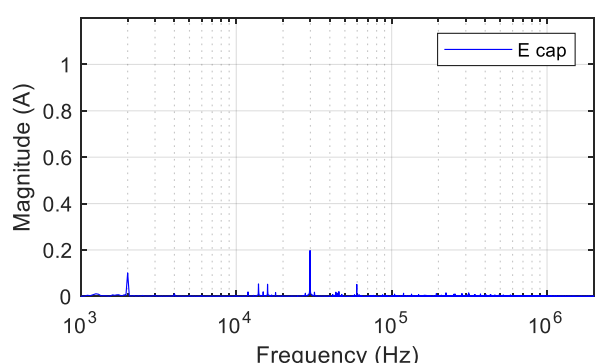

(f) motor current $=6(\mathrm{~A})$

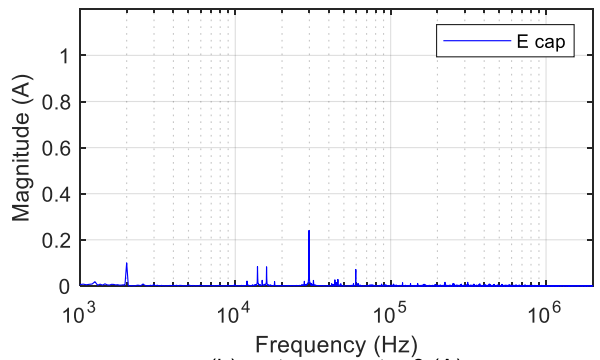

(h) motor current $=8(\mathrm{~A})$

Figure 18. Frequency spectra of the capacitor current as functions of frequency at the motor speed of $5000 \mathrm{rpm}$.

According to the Figure 19, the voltage ripple of electrolytic capacitor was (a) and the one from film capacitor was (b). The variation of DC voltage from the electrolytic capacitor was 3 times higher than the one from the film capacitor. This is because the capacitance of film capacitor was 8 times smaller than that of the electrolytic capacitor.

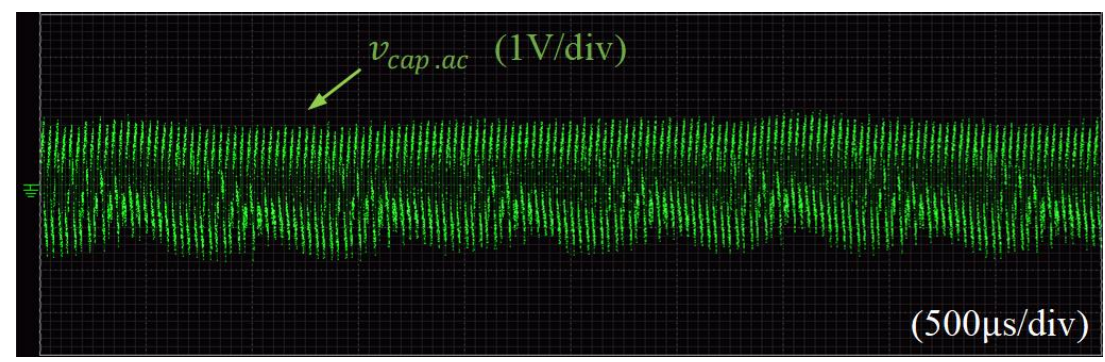

(a)

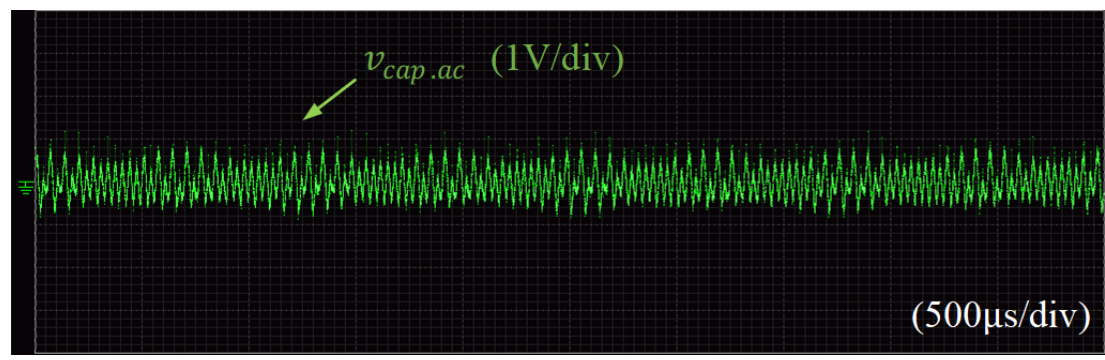

(b)

Figure 19. AC component of capacitor voltages (1 V/div, $500 \mu \mathrm{s} / \mathrm{div})$ from (a) the electrolytic capacitor and (b) the film capacitor.

Figure 20a shows the maximum voltage ripple of the DC link capacitor by current. As the current increased, the voltage ripple on the DC link capacitor tended to increase, and it is seen that the electrolytic capacitor had a larger value compared to the film capacitor. 


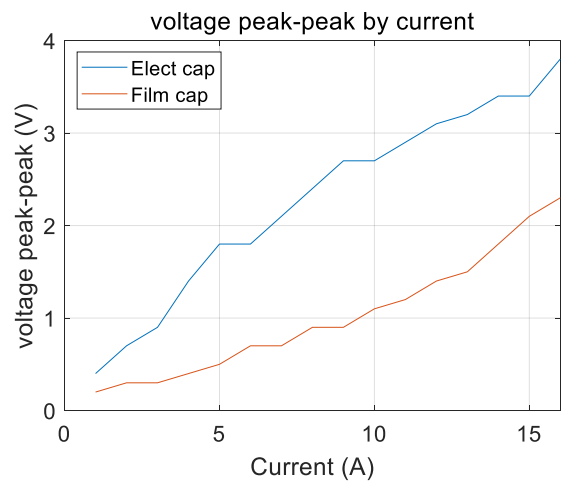

(a)

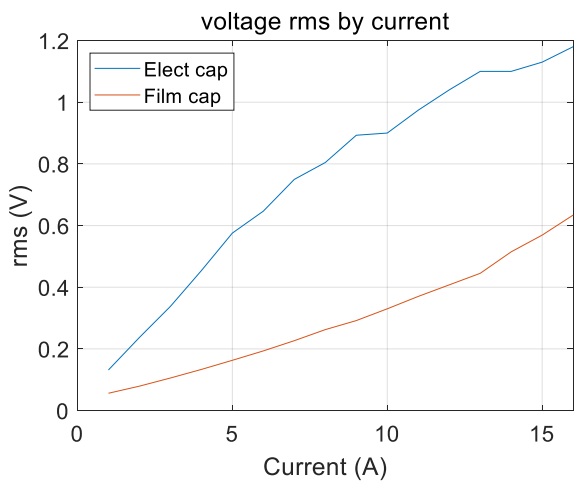

(b)

Figure 20. (a) Peak-to-peak voltage of capacitor. (b) RMS value of the AC component of capacitor voltage obtained by the electrolytic and film capacitors versus motor currents.

Figure 20b shows the RMS value of the voltage ripple of the DC link capacitor by current. As the current increased, the value tended to increase, and you can see that the electrolytic capacitor had a larger value compared to the film capacitor.

Tables 4 and 5 show a summary of Figure 21 as a table. Figure 21 and Tables 4 and 5 show capacitors RMS current versus motor speed. It is seen that the RMS currents of the DC-link currents with the film capacitor based VSI were higher than those by the VSI with the electrolytic capacitor in all operating speed ranges of the IPM.

Table 4. Capacitor RMS current at a speed range of 800-2000 rpm.

\begin{tabular}{ccccccc}
\hline Speed (rpm) & \multicolumn{2}{c}{$\mathbf{8 0 0}$} & \multicolumn{2}{c}{$\mathbf{1 0 0 0}$} & \multicolumn{2}{c}{2000} \\
\hline Current (A) & Film (A) & Elect (A) & Film (A) & Elect (A) & Film (A) & Elect (A) \\
\hline 1 & 0.15 & 0.14 & 0.17 & 0.16 & 0.28 & 0.27 \\
2 & 0.26 & 0.23 & 0.30 & 0.28 & 0.55 & 0.51 \\
3 & 0.38 & 0.35 & 0.45 & 0.42 & 0.81 & 0.77 \\
4 & 0.51 & 0.59 & 0.60 & 0.56 & 1.10 & 1.03 \\
5 & 0.65 & 0.60 & 0.76 & 0.71 & 1.37 & 1.29 \\
6 & 0.79 & 0.73 & 0.94 & 0.87 & 1.66 & 1.55 \\
7 & 0.94 & 0.86 & 1.11 & 1.03 & 1.97 & 1.82 \\
8 & 1.10 & 0.99 & 1.30 & 1.19 & 2.26 & 2.09 \\
9 & 1.27 & 1.14 & 1.48 & 1.37 & 2.58 & 2.39 \\
10 & 1.43 & 1.31 & 1.69 & 1.54 & 2.89 & 2.66 \\
11 & 1.62 & 1.47 & 1.88 & 1.72 & 3.22 & 2.96 \\
12 & 1.79 & 1.62 & 2.10 & 1.91 & 3.54 & 3.23 \\
13 & 2.00 & 1.78 & 2.31 & 2.08 & 3.89 & 3.51 \\
14 & 2.20 & 1.94 & 2.52 & 2.26 & 4.24 & 3.78 \\
15 & 2.40 & 2.11 & 2.74 & 2.45 & 4.58 & 4.08 \\
16 & 2.61 & 2.29 & 2.94 & 2.64 & 4.95 & 4.35 \\
17 & 2.79 & 2.46 & 3.19 & 2.85 & 5.26 & 4.64 \\
18 & 2.99 & 2.65 & 3.47 & 3.03 & N/A & N/A \\
19 & 3.22 & 2.83 & 3.67 & 3.22 & N/A & N/A \\
20 & 3.46 & 3.04 & 3.94 & 3.43 & N/A & N/A \\
\hline
\end{tabular}


Table 5. Capacitor RMS current at a speed range of 3000-6000 rpm.

\begin{tabular}{ccccccccc}
\hline Speed (rpm) & \multicolumn{2}{c}{3000} & \multicolumn{2}{c}{4000} & \multicolumn{2}{c}{5000} & \multicolumn{2}{c}{$\mathbf{6 0 0 0}$} \\
\hline Current (A) & Film (A) & Elect (A) & Film (A) & Elect (A) & Film (A) & Elect (A) & Film (A) & Elect (A) \\
\hline 1 & 0.38 & 0.34 & 0.47 & 0.47 & 0.60 & 0.57 & 1.36 & 0.61 \\
2 & 0.77 & 0.70 & 0.97 & 0.91 & 1.19 & 1.15 & 1.66 & 1.36 \\
3 & 1.15 & 1.06 & 1.47 & 1.39 & 1.79 & 1.72 & 2.36 & 2.02 \\
4 & 1.56 & 1.42 & 2.01 & 2.33 & 2.43 & 2.30 & 3.10 & 2.69 \\
5 & 1.95 & 1.78 & 2.52 & 2.33 & 3.08 & 2.88 & 4.07 & 3.34 \\
6 & 2.37 & 2.16 & 3.06 & 2.83 & 3.73 & 3.51 & N/A & N/A \\
7 & 2.78 & 2.54 & 3.63 & 3.33 & 4.42 & 4.10 & N/A & N/A \\
8 & 3.24 & 2.94 & 4.20 & 3.84 & 5.11 & 4.76 & N/A & N/A \\
9 & 3.67 & 3.34 & 4.76 & 4.36 & 5.89 & 5.35 & N/A & N/A \\
10 & 4.09 & 3.74 & 5.32 & 4.87 & 6.53 & 5.97 & N/A & N/A \\
11 & 4.53 & 4.15 & 5.93 & 5.39 & 7.36 & 6.59 & N/A & N/A \\
12 & 5.05 & 4.55 & 6.57 & 5.88 & N/A & N/A & N/A & N/A \\
13 & 5.46 & 4.96 & 7.24 & 6.38 & N/A & N/A & N/A & N/A \\
14 & 6.05 & 5.36 & 7.97 & 6.86 & N/A & N/A & N/A & N/A \\
15 & 6.60 & 5.74 & 8.84 & 7.35 & N/A & N/A & N/A & N/A \\
16 & 7.18 & 6.12 & N/A & N/A & N/A & N/A & N/A & N/A \\
17 & N/A & N/A & N/A & N/A & N/A & N/A & N/A & N/A \\
18 & N/A & N/A & N/A & N/A & N/A & N/A & N/A & N/A \\
19 & N/A & N/A & N/A & N/A & N/A & N/A & N/A & N/A \\
20 & N/A & N/A & N/A & N/A & N/A & N/A & N/A & N/A
\end{tabular}

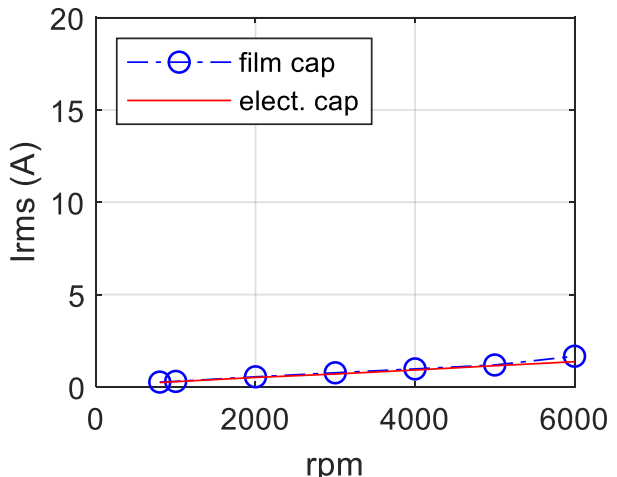

(a) motor current $=2(\mathrm{~A})$

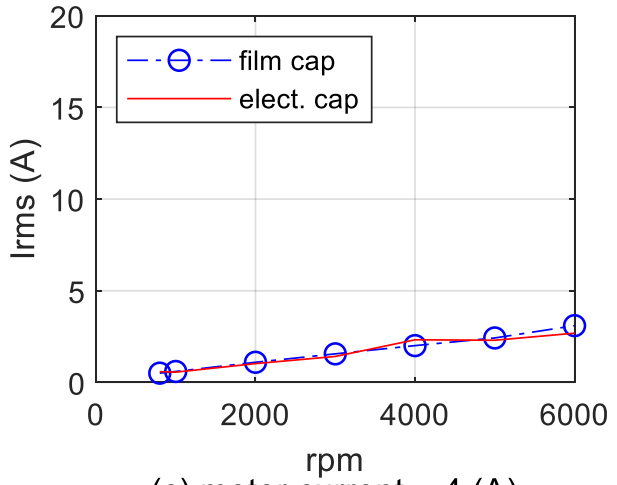

(c) motor current $=4(\mathrm{~A})$

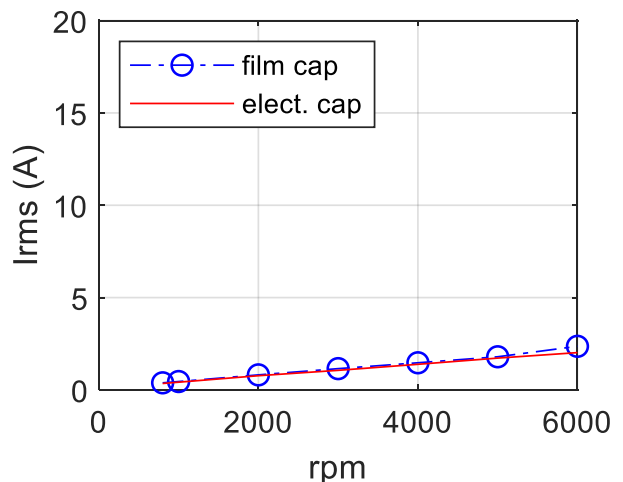

(b) motor current $=3(\mathrm{~A})$

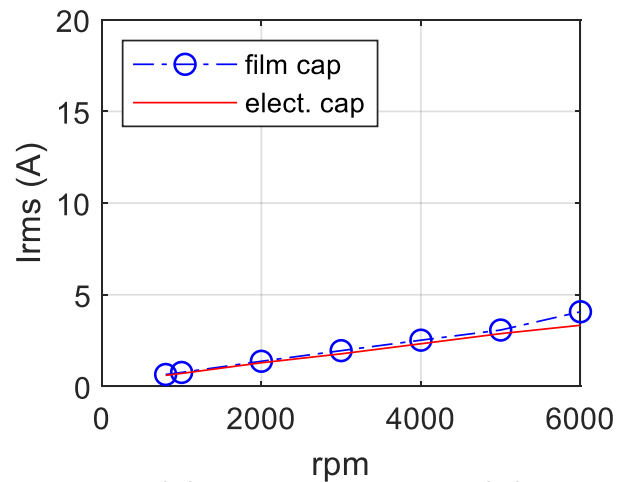

(d) motor current $=5(\mathrm{~A})$

Figure 21. Cont. 


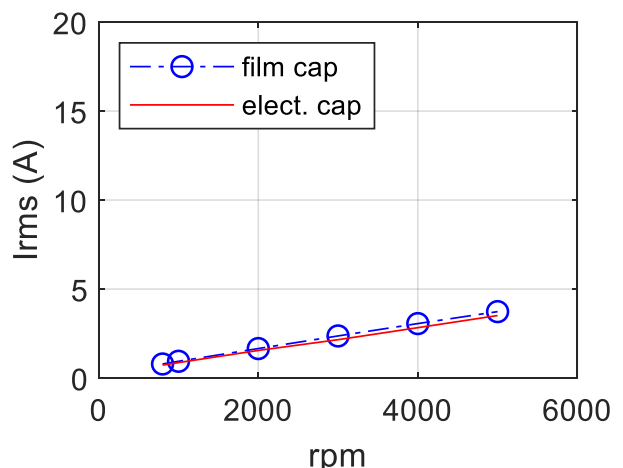

(e) motor current $=6(\mathrm{~A})$

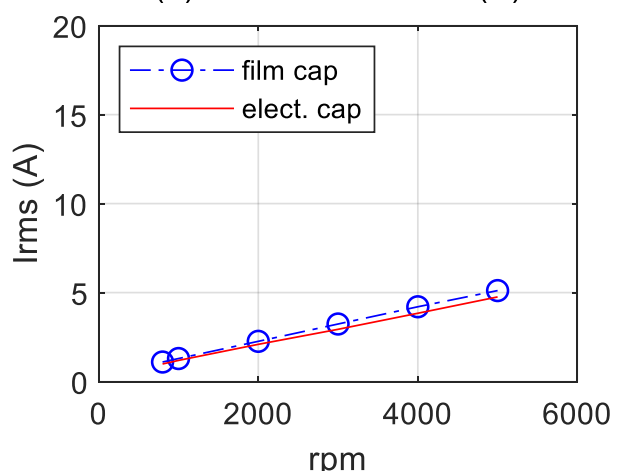

(g) motor current $=8(\mathrm{~A})$

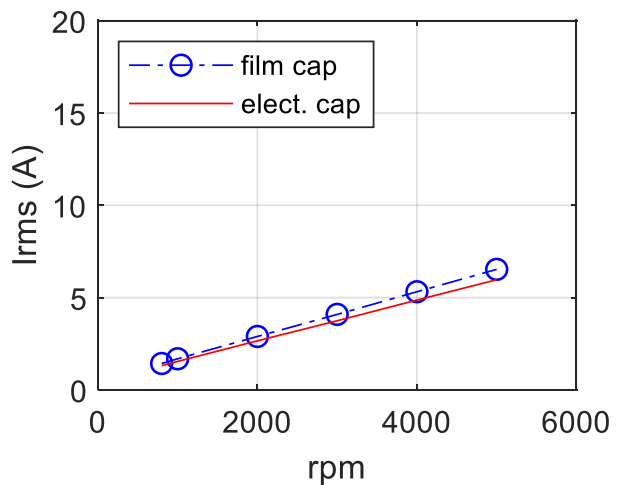

(i) motor current $=10(\mathrm{~A})$

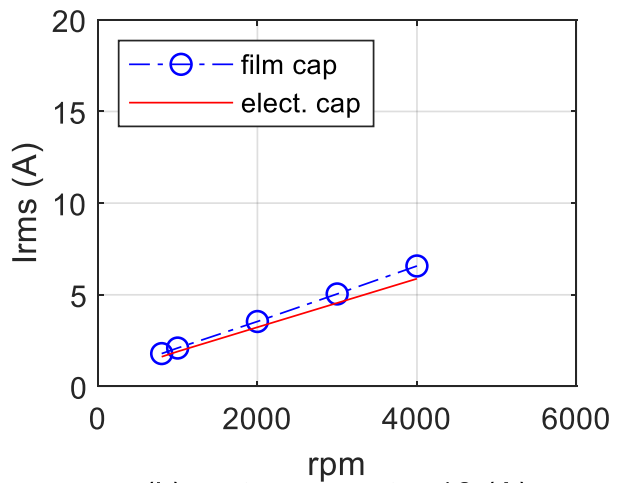

(k) motor current $=12(\mathrm{~A})$

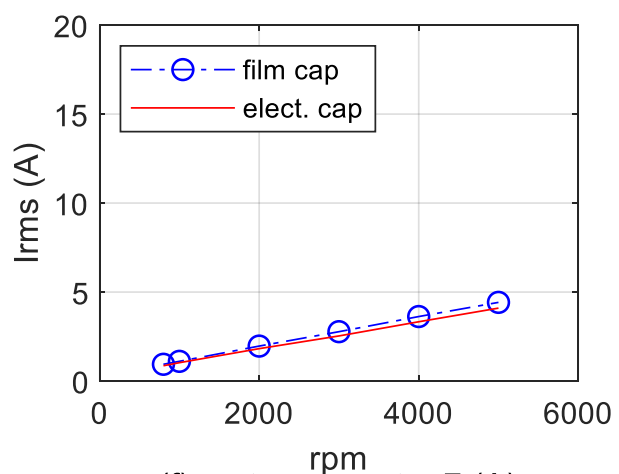

(f) motor current $=7$ (A)

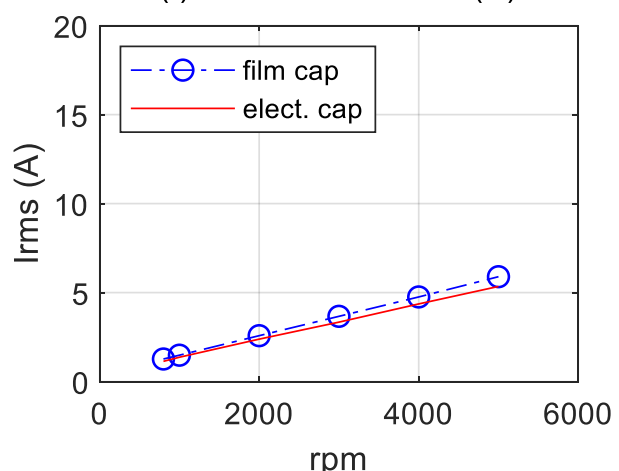

(h) motor current $=9(\mathrm{~A})$

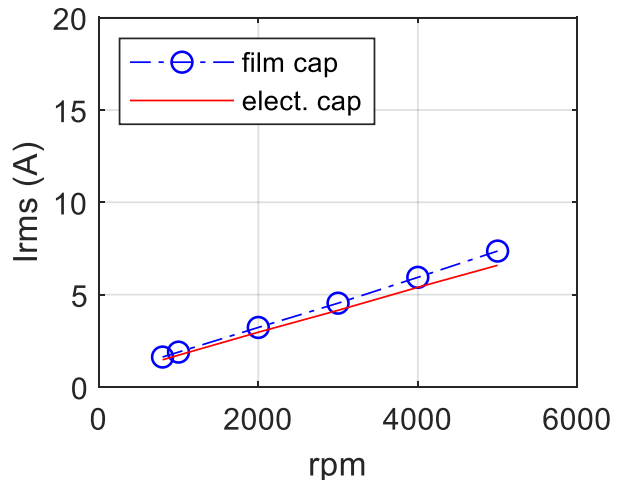

(j) motor current $=11(\mathrm{~A})$

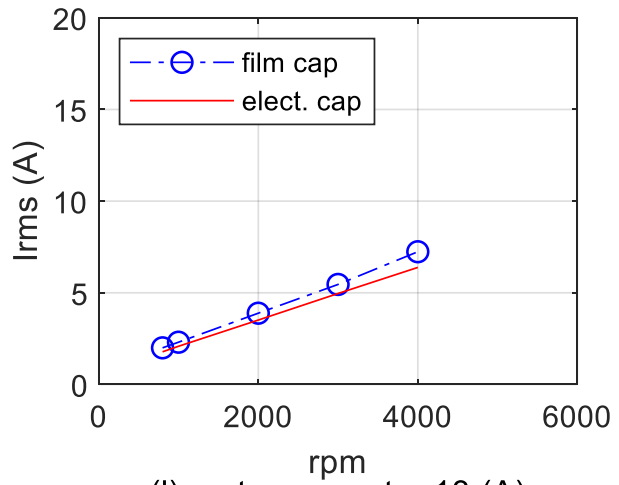

(I) motor current $=13(\mathrm{~A})$

Figure 21. Cont. 

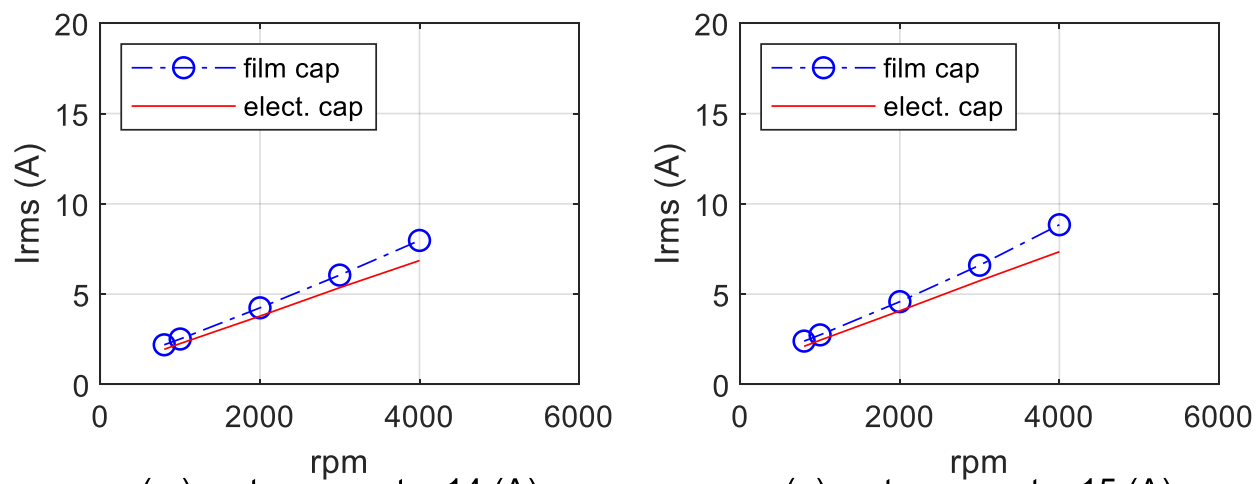

(m) motor current $=14(\mathrm{~A})$

(n) motor current $=15(\mathrm{~A})$
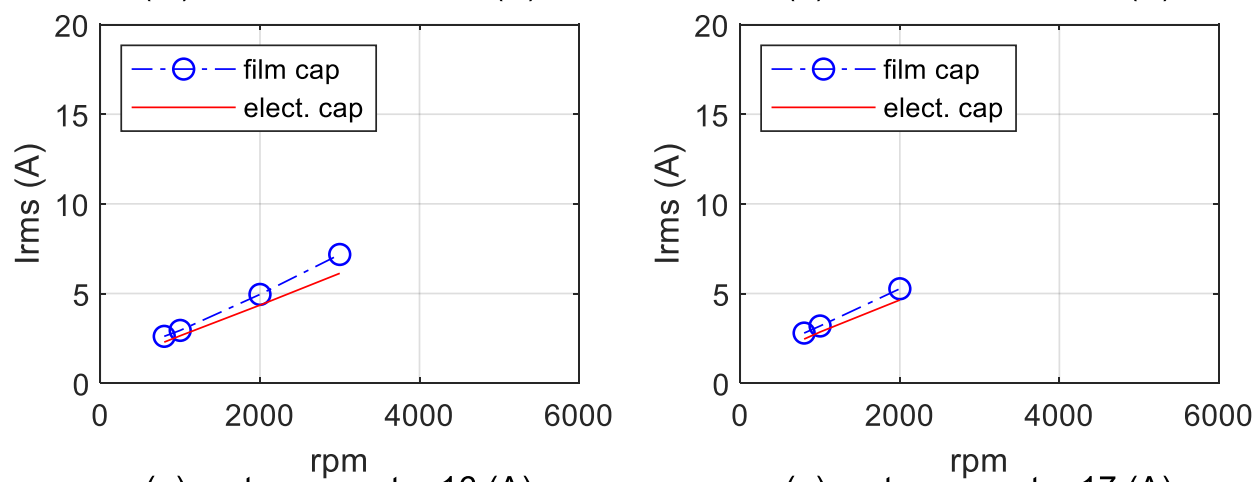

(o) motor current $=16(\mathrm{~A})$

(p) motor current $=17(\mathrm{~A})$

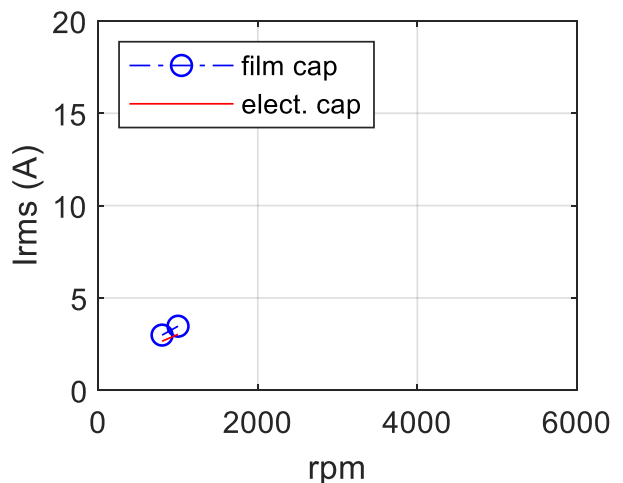

(q) motor current $=18(\mathrm{~A})$

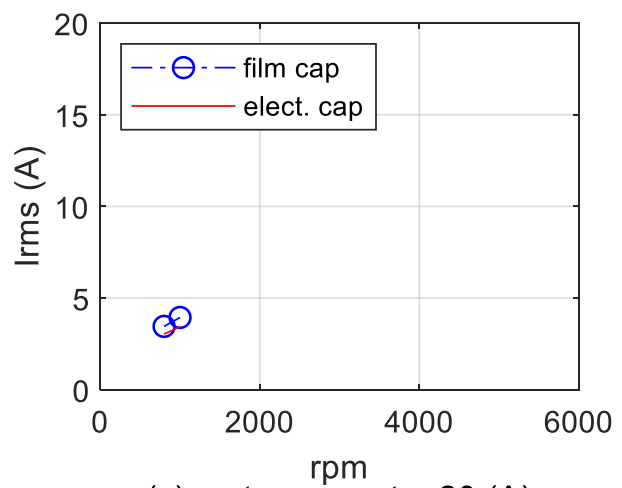

(s) motor current $=20(\mathrm{~A})$

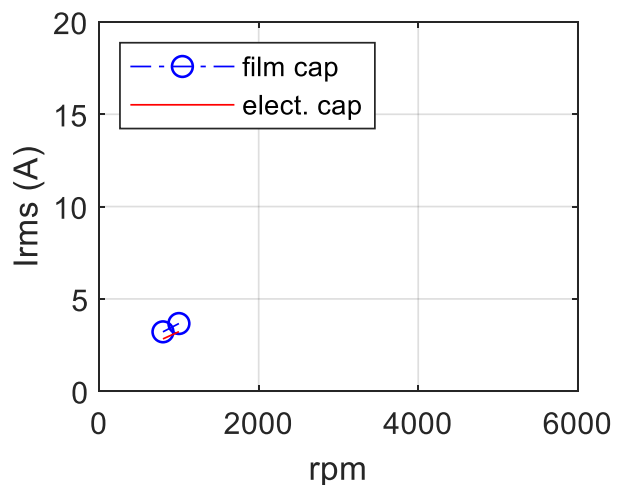

(r) motor current $=19(\mathrm{~A})$

Figure 21. Capacitors RMS current as functions of motor speed. 


\subsection{Characteristics of Losses and Junction Temperatures of Two Capacitors Used in Electric Compressor Systems}

Capacitor losses can be calculated with the ESR values $\operatorname{ESR}\left(f_{i}\right)$ and the capacitor currents $I_{a c}\left(f_{i}\right)$ in the same frequency as

$$
\text { Loss }=\sum \operatorname{ESR}\left(f_{i}\right) \times I_{a c}^{2}\left(f_{i}\right)
$$

Figure 22 illustrates losses resulted from the electrolytic capacitor and the film capacitor installed in the VSI for the electric compressor systems, versus motor currents and motor speeds. It is seen that both losses of the two capacitors were proportional to the motor speeds as well as the motor currents. For all operational regions, the losses in electrolytic capacitor were higher than the film cap. However, in the other area of motor current $11 \mathrm{~A}$ or more and motor speed $5000 \mathrm{rpm}$ or more, different results are shown. This will be described at the next section.

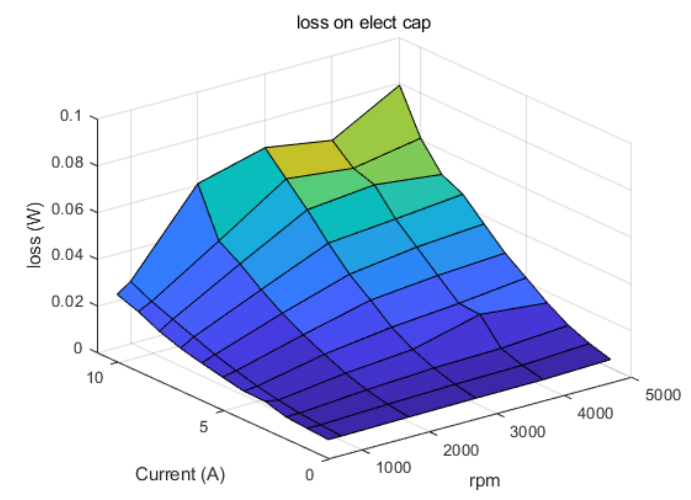

(a)

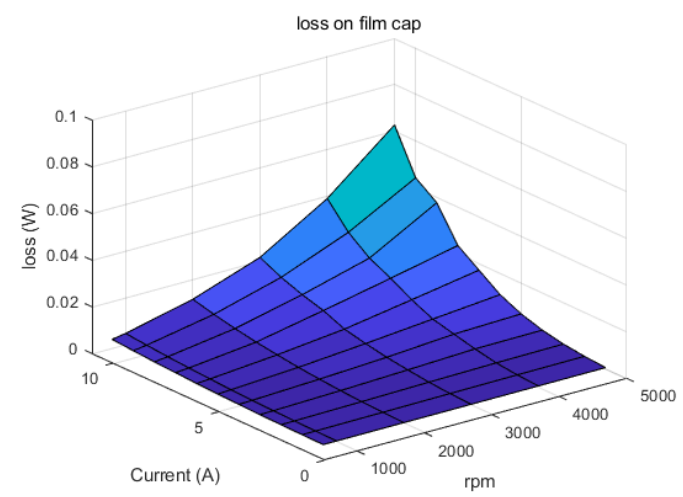

(b)

Figure 22. Capacitor losses in (a) electrolytic capacitor $(88 \mu \mathrm{F})$ and (b) film capacitor $(10 \mu \mathrm{F})$ as functions of motor speed and motor current of the electric compressor system.

Comparative results of losses in the two capacitors used in the electric compressor systems are depicted in Figure 23. The losses of the film capacitors were smaller than those of the electrolytic capacitors for most of the operating regions considered in the electric compressor systems, due to the smaller ESR values. For electrolytic capacitors, the loss decreased in the section where the speed of the motor was above about $3000-4000 \mathrm{rpm}$ as it is shown Figure $23 \mathrm{~m}$. Over this region, the loss of film capacitors became greater. This can be seen at Figure $23 \mathrm{~m}-\mathrm{s}$. This is related to what was mentioned in Figure 19 above. Tables 6 and 7 shows comparative results of losses in the two capacitors at a speed range of 800-2000 rpm and 3000-6000 rpm, respectively, where losses increase with increasing speed.

The junction temperatures of the two capacitors can be estimated with the power losses of the capacitors and the thermal resistances.

$$
\mathrm{T}_{\text {case }}=T_{a m b}+R_{t h} \times \sum E S R\left(f_{i}\right) \times I_{a c}^{2}\left(f_{i}\right)
$$

The heat generated by the capacitor can be estimated through Equation (3). Equation (3) is represented in [19]. $T_{\text {case }}$ is the surface temperature of the capacitor, $T_{a m b}$ is the ambient temperature and it was assumed to be $25^{\circ} \mathrm{C}$ and $R_{t h}$ is the thermal resistance of the capacitor. In the case of the thermal resistance of the film capacitor, in order to find out the difference between the electrolytic capacitor and the film capacitor, the thermal resistance of the film capacitor having a volume similar to that of the electrolytic capacitor was selected. Thermal resistance of the film capacitor is represented on its datasheet [17]. In the case of electrolytic capacitors, the volume of the parameter determining the thermal resistance is the main [20], so the data of the application note [21] can be used. 


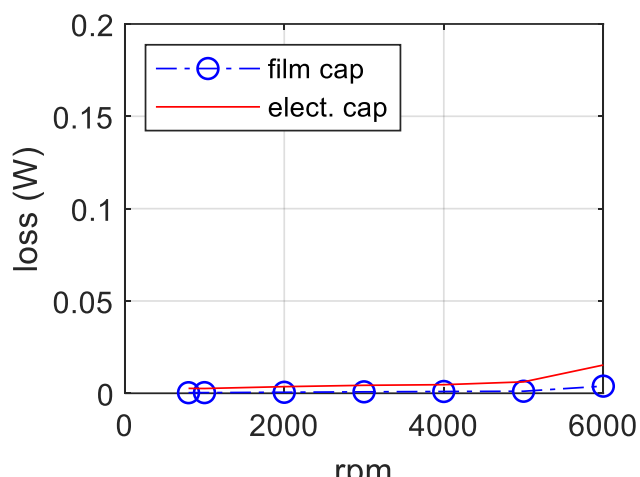

(a) motor current $=2(\mathrm{~A})$

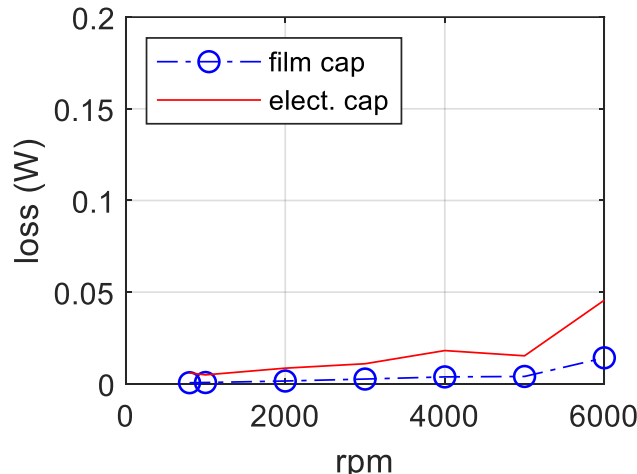

(c) motor current $=4(\mathrm{~A})$

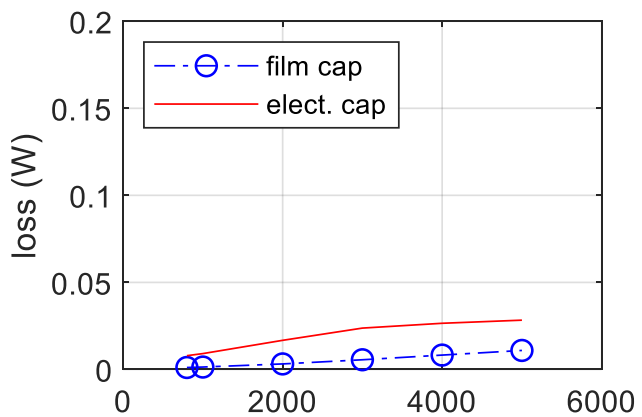

(e) motor current $=6(\mathrm{~A})$

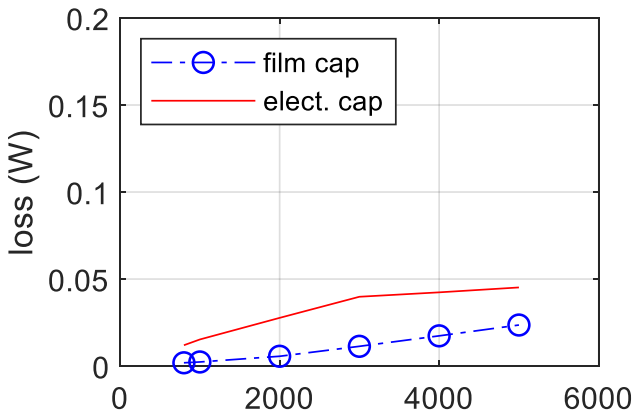

(g) motor clurrent $=8(A)$

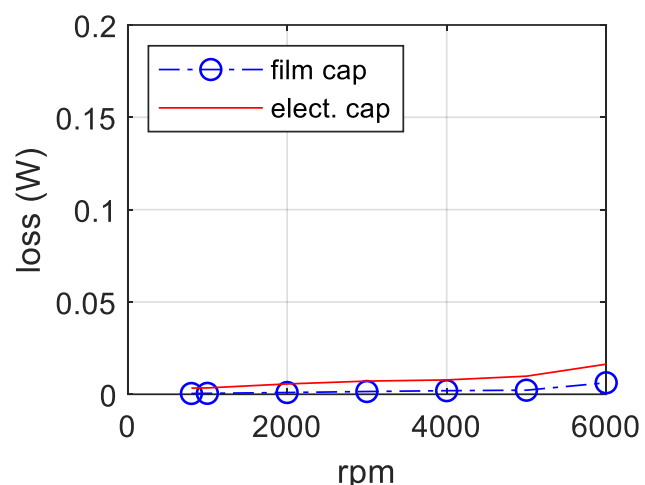

(b) motor current $=3(\mathrm{~A})$

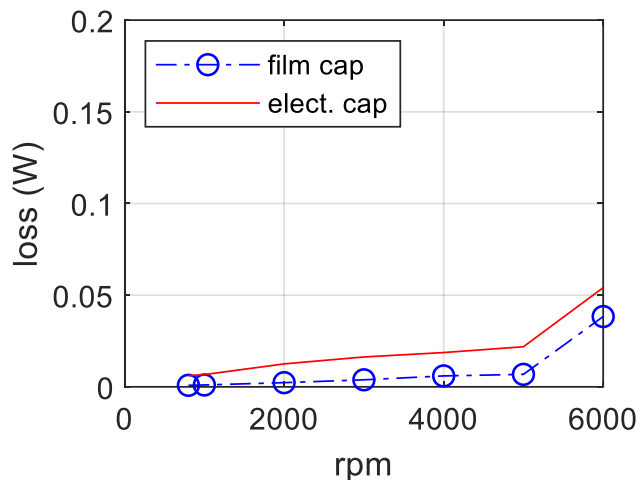

(d) motor current $=5$ (A)

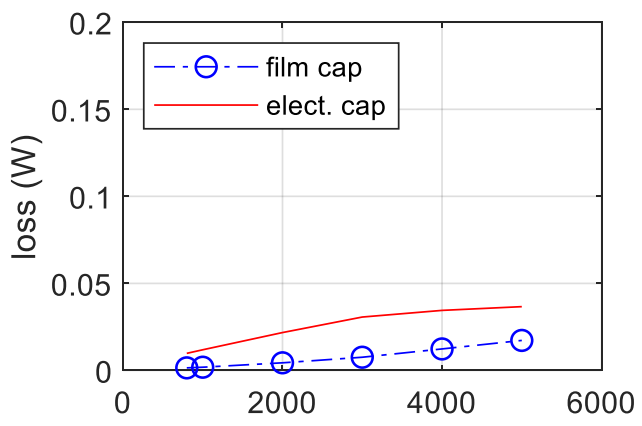

(f) motor current $=7(\mathrm{~A})$

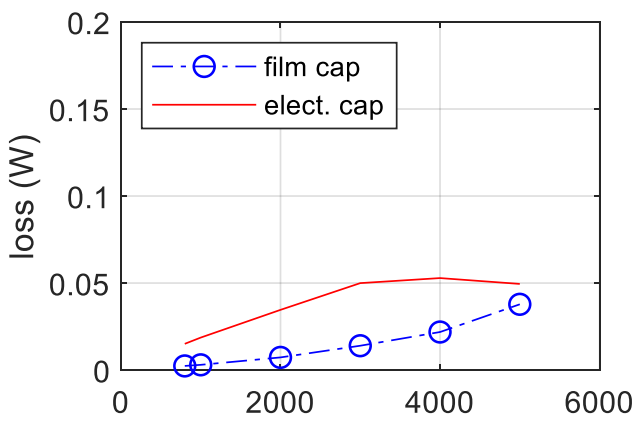

(h) motor current $=9(\mathrm{~A})$

Figure 23. Cont. 


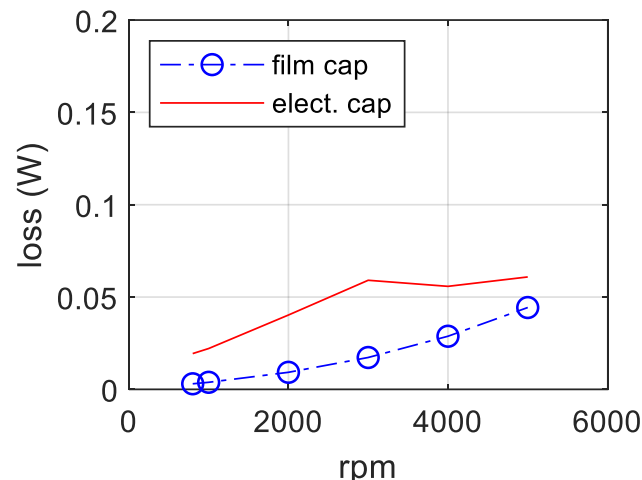

(i) motor current $=10(\mathrm{~A})$

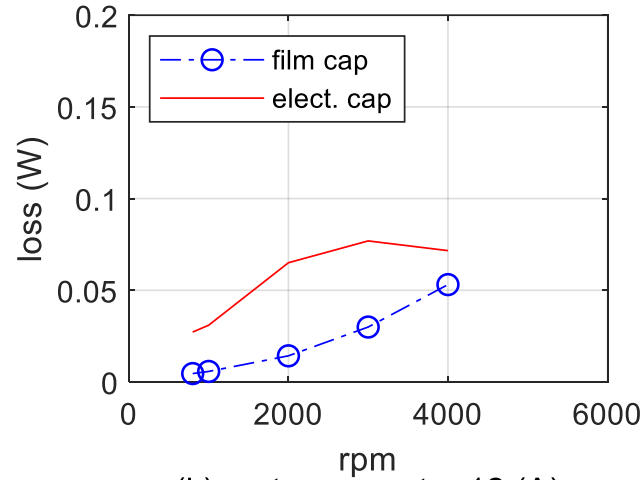

(k) motor current $=12(\mathrm{~A})$

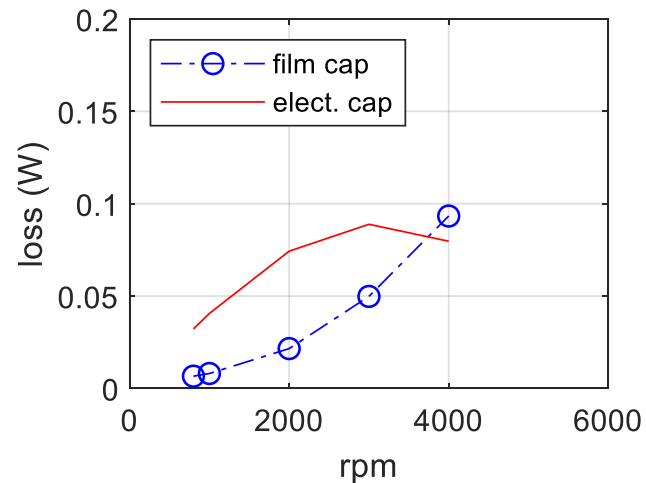

(m) motor current $=14(\mathrm{~A})$

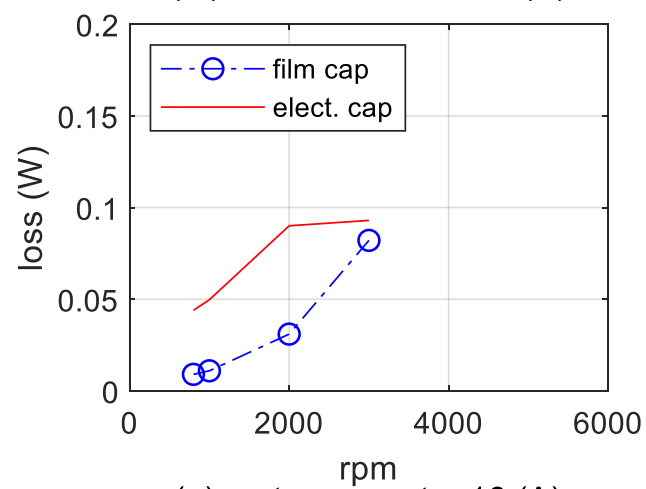

(o) motor current $=16(\mathrm{~A})$

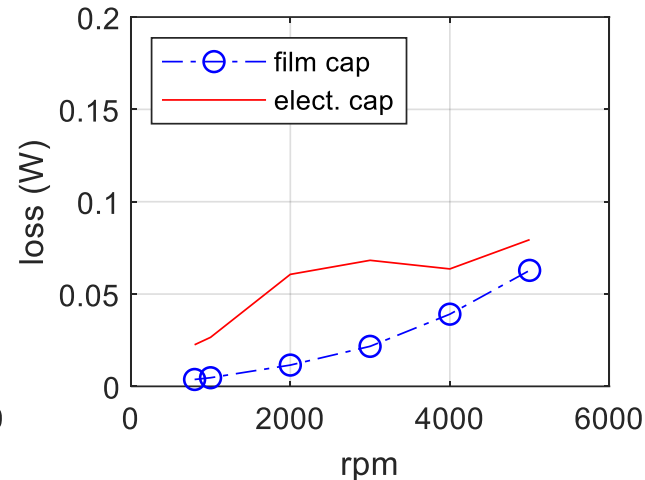

(j) motor current $=11(\mathrm{~A})$

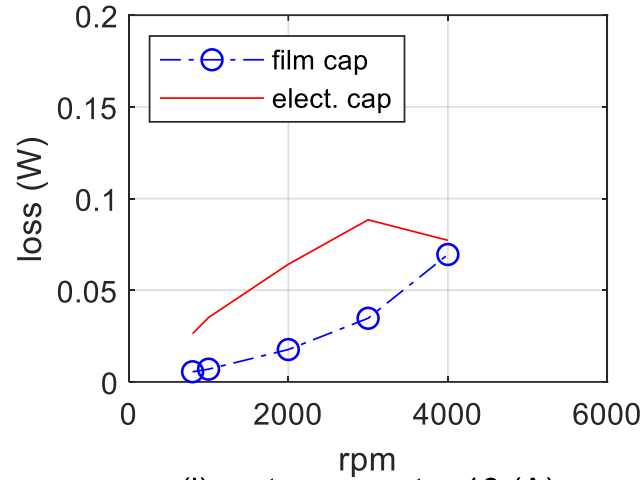

(I) motor current $=13(\mathrm{~A})$

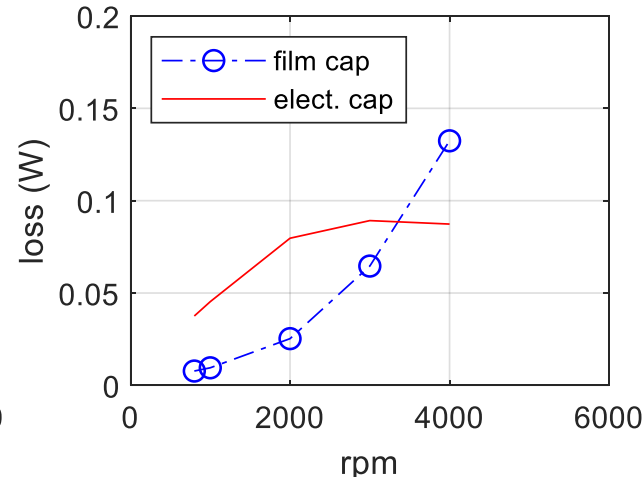

(n) motor current $=15(\mathrm{~A})$

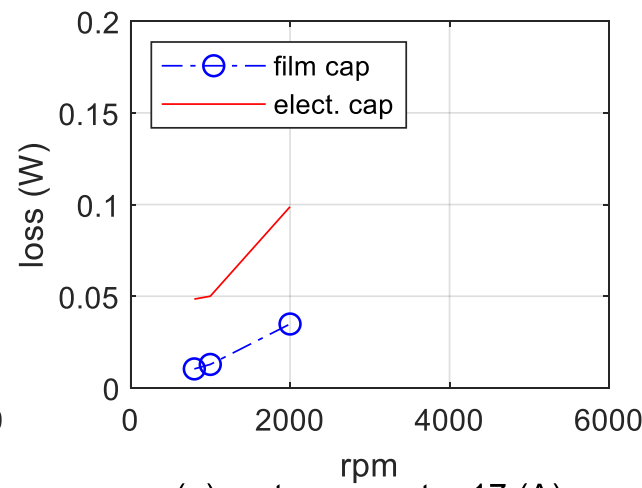

(p) motor current $=17(\mathrm{~A})$

Figure 23. Cont. 


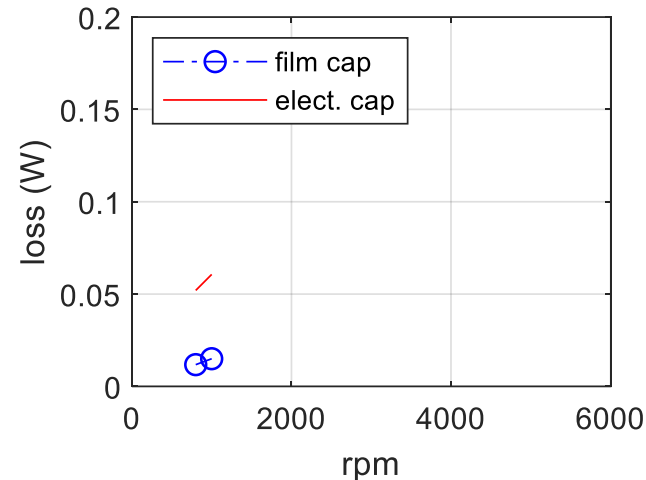

(q) motor current $=18(\mathrm{~A})$

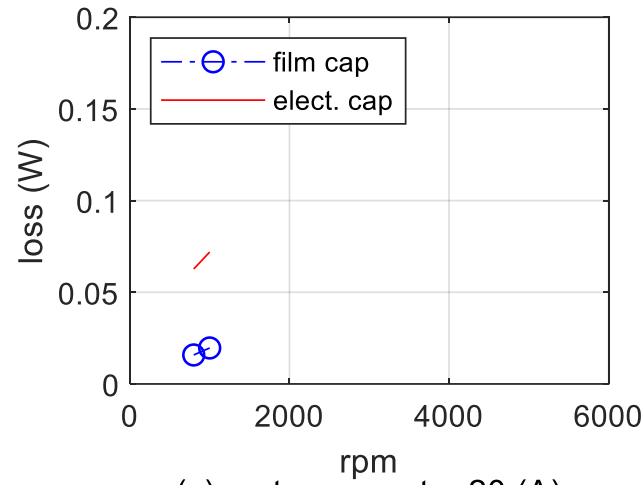

(s) motor current $=20(\mathrm{~A})$

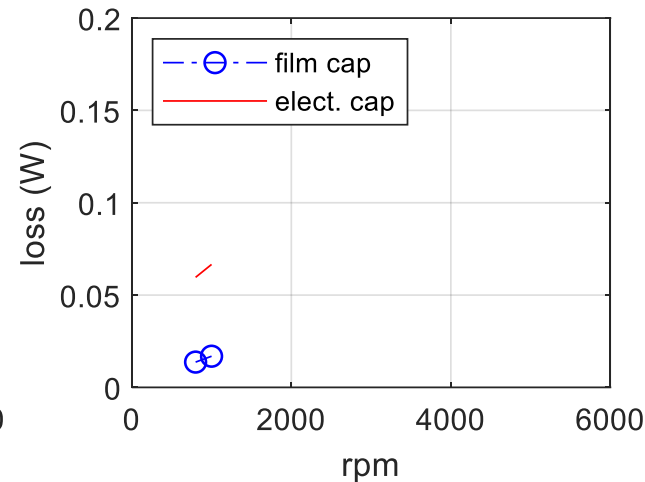

(r) motor current $=19(\mathrm{~A})$

Figure 23. Comparative results of losses in the two capacitors used in the electric compressor systems.

Table 6. Comparative results of losses in the two capacitors at a speed range of 800-2000 rpm.

\begin{tabular}{ccccccc}
\hline Speed (rpm) & \multicolumn{2}{c}{$\mathbf{8 0 0}$} & \multicolumn{2}{c}{$\mathbf{1 0 0 0}$} & \multicolumn{2}{c}{ 2000 } \\
\hline Current (A) & Film (mW) & Elect $(\mathbf{m W})$ & Film $(\mathbf{m W})$ & Elect $(\mathbf{m W})$ & Film (mW) & Elect (mW) \\
\hline 1 & 0.25 & 1.99 & 0.25 & 1.95 & 0.30 & 2.28 \\
2 & 0.32 & 2.64 & 0.35 & 2.60 & 0.55 & 3.58 \\
3 & 0.44 & 3.34 & 0.51 & 3.46 & 0.95 & 5.59 \\
4 & 0.60 & 5.95 & 0.72 & 4.88 & 1.54 & 8.54 \\
5 & 0.83 & 6.09 & 1.01 & 6.68 & 2.28 & 12.52 \\
6 & 1.12 & 7.91 & 1.38 & 9.09 & 3.16 & 16.72 \\
7 & 1.48 & 9.82 & 1.84 & 11.85 & 4.37 & 21.75 \\
8 & 1.91 & 12.00 & 2.39 & 15.31 & 5.66 & 27.72 \\
9 & 2.41 & 15.10 & 3.04 & 18.69 & 7.31 & 34.62 \\
10 & 3.02 & 19.38 & 3.83 & 22.13 & 9.24 & 40.27 \\
11 & 3.73 & 22.54 & 4.68 & 26.55 & 11.52 & 60.66 \\
12 & 4.55 & 27.20 & 5.72 & 30.93 & 14.23 & 65.01 \\
13 & 5.54 & 26.32 & 6.95 & 35.12 & 17.66 & 64.16 \\
14 & 6.59 & 32.20 & 8.05 & 40.56 & 21.54 & 74.29 \\
15 & 7.76 & 37.55 & 9.51 & 45.32 & 25.29 & 79.69 \\
16 & 9.03 & 43.97 & 10.97 & 49.72 & 30.97 & 90.05 \\
17 & 10.36 & 48.44 & 12.80 & 50.00 & 34.85 & 98.81 \\
18 & 11.77 & 51.98 & 14.98 & 60.65 & N/A & N/A \\
19 & 13.70 & 59.61 & 16.88 & 66.60 & N/A & N/A \\
20 & 15.81 & 62.69 & 19.62 & 71.93 & N/A & N/A \\
\hline
\end{tabular}

Thermal resistance of the electrolytic and film capacitor from the junction of the capacitor to the case was $8.62\left({ }^{\circ} \mathrm{C} / \mathrm{W}\right)$ and $22.72\left({ }^{\circ} \mathrm{C} / \mathrm{W}\right)$, respectively.

Figure 24 is plotted by using Equation (3). Figure 24 shows the heat generated by the film capacitor and the electrolytic capacitor and is drawn as functions of the motor current. As it is studied in Figure 24, the heat generated by the film cap in the region where the speed and current were increased 
became larger than the heat generated by the electrolytic cap. That region is shown at Figure $24 \mathrm{c}$ when the motor current was larger than $13 \mathrm{~A}$ at motor speed $3000 \mathrm{rpm}$. The current value at this intersection became lower as the motor speed increased. This is shown on Figure 24d,e.

Tables 8 and 9 show a summary of Figures 24 and 25. Figure 25 is plotted by using Equation (3). As shown in Figure 25 and Tables 8 and 9, in the low-speed, low-current region, heat generation was insignificant, but the higher the speed, the higher the heat generated in both capacitors. As it is studied in Figure 24, the heat generated by the film cap in the region where the speed and current were increased became larger than the heat generated by the electrolytic capacitor. That region is shown at Figure $25 \mathrm{f}$ when the motor speed was higher than $4000 \mathrm{rpm}$ at the motor current that was $7 \mathrm{~A}$. The speed value at this intersection would get lower as the motor current gets larger.

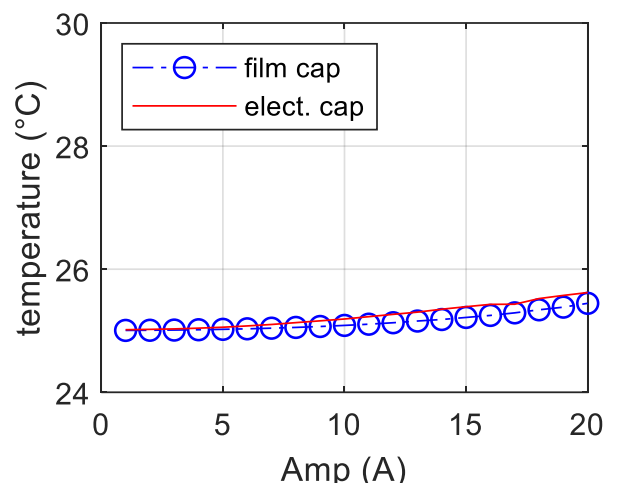

(a) motor speed $=1000(\mathrm{rpm})$

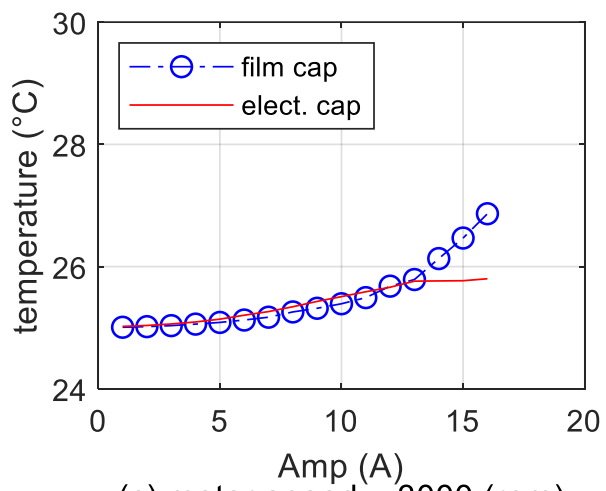

(c) motor speed $=3000(\mathrm{rpm})$

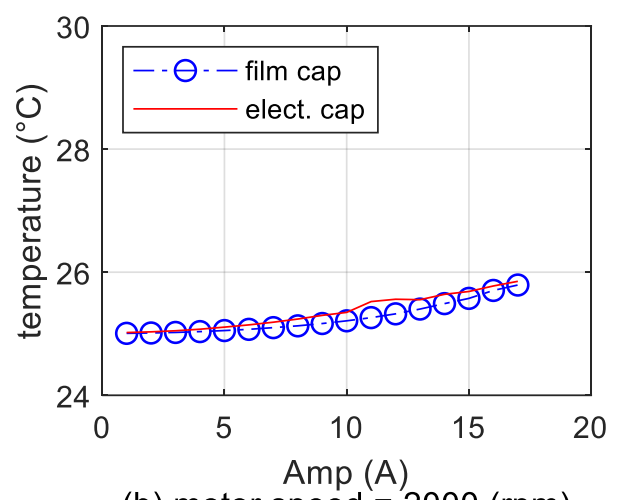

(b) motor speed $=2000(\mathrm{rpm})$

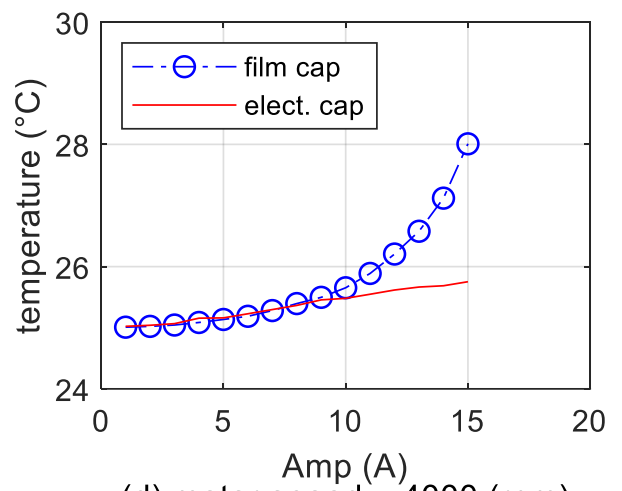

(d) motor speed $=4000(\mathrm{rpm})$

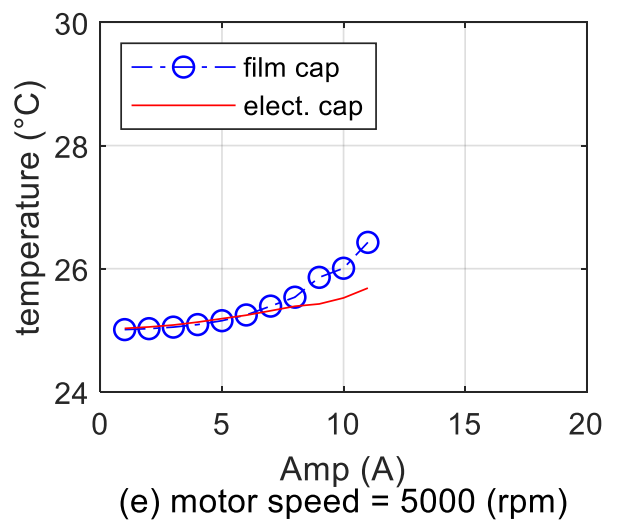

Figure 24. Heat generation by the electrolytic and film capacitor as functions of the motor current. 
Table 7. Comparative results of losses in the two capacitors at a speed range of 3000-6000 rpm.

\begin{tabular}{ccccccccc}
\hline Speed (rpm) & \multicolumn{2}{c}{3000} & \multicolumn{2}{c}{4000} & \multicolumn{2}{c}{5000} & \multicolumn{2}{c}{6000} \\
\hline Current (A) & $\begin{array}{c}\text { Film } \\
(\mathbf{m W})\end{array}$ & $\begin{array}{c}\text { Elect } \\
\mathbf{( m W )}\end{array}$ & $\begin{array}{c}\text { Film } \\
\mathbf{( m W )}\end{array}$ & $\begin{array}{c}\text { Elect } \\
\mathbf{( m W )}\end{array}$ & $\begin{array}{c}\text { Film } \\
\mathbf{( m W )}\end{array}$ & $\begin{array}{c}\text { Elect } \\
\mathbf{( m W )}\end{array}$ & $\begin{array}{c}\text { Film } \\
\mathbf{( m W )}\end{array}$ & $\begin{array}{c}\text { Elect } \\
\mathbf{( m W})\end{array}$ \\
\hline 1 & 0.34 & 2.56 & 0.39 & 2.68 & 0.44 & 3.50 & 9.79 & 14.59 \\
2 & 0.78 & 4.31 & 0.97 & 4.66 & 1.12 & 6.17 & 3.87 & 15.31 \\
3 & 1.50 & 7.14 & 1.95 & 7.78 & 2.22 & 9.80 & 6.23 & 16.30 \\
4 & 2.61 & 10.95 & 3.78 & 18.14 & 4.02 & 15.28 & 14.19 & 45.63 \\
5 & 3.83 & 16.29 & 5.95 & 18.70 & 6.80 & 21.86 & 38.34 & 54.10 \\
6 & 5.55 & 23.75 & 8.24 & 26.50 & 10.91 & 28.31 & N/A & N/A \\
7 & 7.58 & 30.67 & 12.35 & 34.48 & 17.23 & 36.63 & N/A & N/A \\
8 & 11.38 & 39.84 & 17.39 & 42.38 & 23.61 & 45.19 & N/A & N/A \\
9 & 14.01 & 49.98 & 21.89 & 52.87 & 37.81 & 49.51 & N/A & N/A \\
10 & 17.27 & 59.07 & 28.77 & 55.80 & 44.33 & 60.89 & N/A & N/A \\
11 & 21.68 & 68.27 & 39.10 & 63.60 & 62.82 & 79.43 & N/A & N/A \\
12 & 29.93 & 76.90 & 53.07 & 71.61 & N/A & N/A & N/A & N/A \\
13 & 34.71 & 88.42 & 69.48 & 77.23 & N/A & N/A & N/A & N/A \\
14 & 49.79 & 88.85 & 93.32 & 79.68 & N/A & N/A & N/A & N/A \\
15 & 64.59 & 89.22 & 132.44 & 87.34 & N/A & N/A & N/A & N/A \\
16 & 82.10 & 92.98 & N/A & N/A & N/A & N/A & N/A & N/A \\
17 & N/A & N/A & N/A & N/A & N/A & N/A & N/A & N/A \\
18 & N/A & N/A & N/A & N/A & N/A & N/A & N/A & N/A \\
19 & N/A & N/A & N/A & N/A & N/A & N/A & N/A & N/A \\
20 & N/A & N/A & N/A & N/A & N/A & N/A & N/A & N/A \\
\hline
\end{tabular}

Table 8. Heat generation by the electrolytic and film capacitor at a speed range of 800-2000 rpm.

\begin{tabular}{ccccccc}
\hline Speed (rpm) & \multicolumn{2}{c}{$\mathbf{8 0 0}$} & \multicolumn{2}{c}{$\mathbf{1 0 0 0}$} & \multicolumn{2}{c}{$\mathbf{2 0 0 0}$} \\
\hline Current (A) & Film $\left({ }^{\circ} \mathbf{C}\right)$ & Elect $\left({ }^{\circ} \mathbf{C}\right)$ & Film $\left({ }^{\circ} \mathbf{C}\right)$ & Elect $\left({ }^{\circ} \mathbf{C}\right)$ & Film $\left({ }^{\circ}\right.$ C) & Elect $\left({ }^{\circ}\right.$ C) \\
\hline 1 & 25.01 & 25.02 & 25.01 & 25.02 & 25.01 & 25.02 \\
2 & 25.01 & 25.02 & 25.01 & 25.02 & 25.01 & 25.03 \\
3 & 25.01 & 25.03 & 25.01 & 25.03 & 25.02 & 25.05 \\
4 & 25.01 & 25.05 & 25.02 & 25.04 & 25.03 & 25.07 \\
5 & 25.02 & 25.05 & 25.02 & 25.06 & 25.05 & 25.11 \\
6 & 25.03 & 25.07 & 25.03 & 25.08 & 25.07 & 25.14 \\
7 & 25.03 & 25.08 & 25.04 & 25.10 & 25.10 & 25.19 \\
8 & 25.04 & 25.10 & 25.05 & 25.13 & 25.13 & 25.24 \\
9 & 25.05 & 25.13 & 25.07 & 25.16 & 25.17 & 25.30 \\
10 & 25.07 & 25.17 & 25.09 & 25.19 & 25.21 & 25.35 \\
11 & 25.08 & 25.19 & 25.11 & 25.23 & 25.26 & 25.52 \\
12 & 25.10 & 25.23 & 25.13 & 25.27 & 25.32 & 25.56 \\
13 & 25.13 & 25.23 & 25.16 & 25.30 & 25.40 & 25.55 \\
14 & 25.15 & 25.28 & 25.18 & 25.35 & 25.49 & 25.64 \\
15 & 25.18 & 25.32 & 25.22 & 25.39 & 25.57 & 25.69 \\
16 & 25.21 & 25.38 & 25.25 & 25.43 & 25.70 & 25.78 \\
17 & 25.24 & 25.42 & 25.29 & 25.43 & 25.79 & 25.85 \\
18 & 25.27 & 25.45 & 25.34 & 25.52 & N/A & N/A \\
19 & 25.31 & 25.51 & 25.38 & 25.57 & N/A & N/A \\
20 & 25.36 & 25.54 & 25.45 & 25.62 & N/A & N/A \\
\hline
\end{tabular}




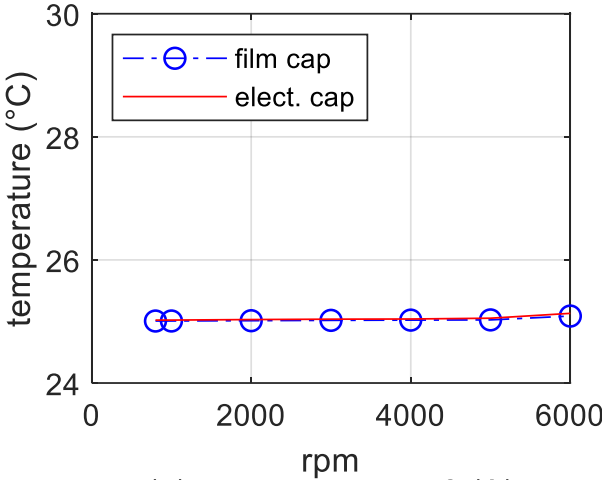

(a) motor current $=2(A)$

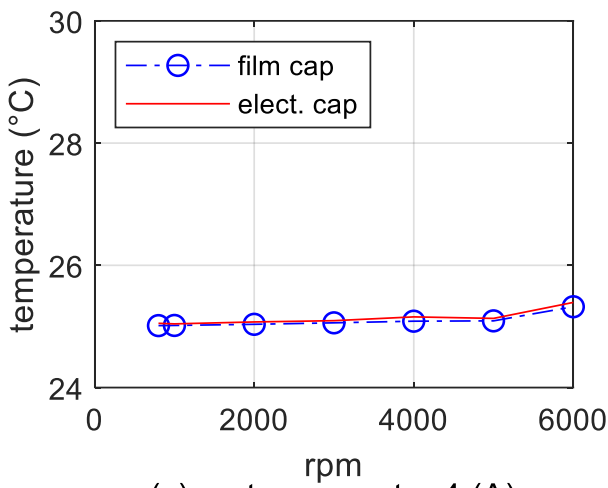

(c) motor current $=4(\mathrm{~A})$

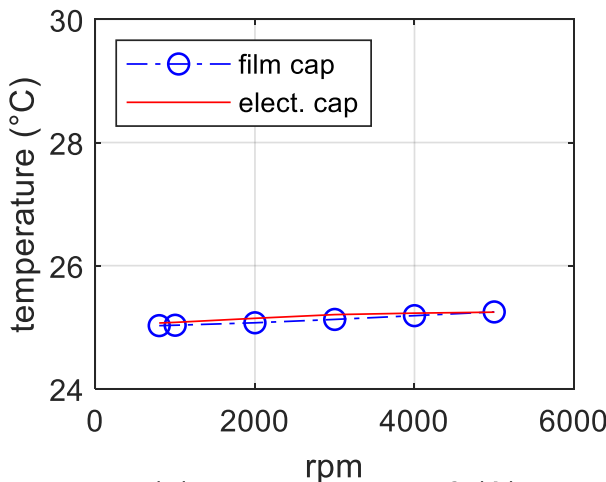

(e) motor current $=6(\mathrm{~A})$

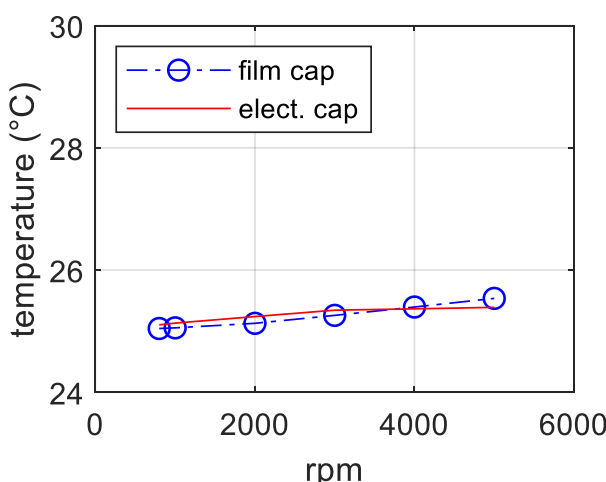

(g) motor current $=8(\mathrm{~A})$

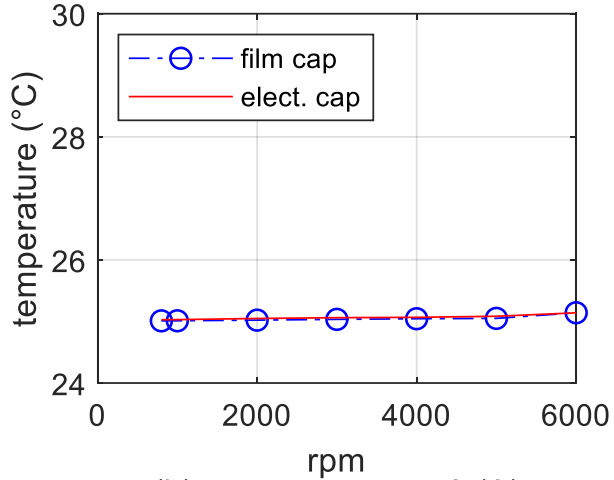

(b) motor current $=3(\mathrm{~A})$

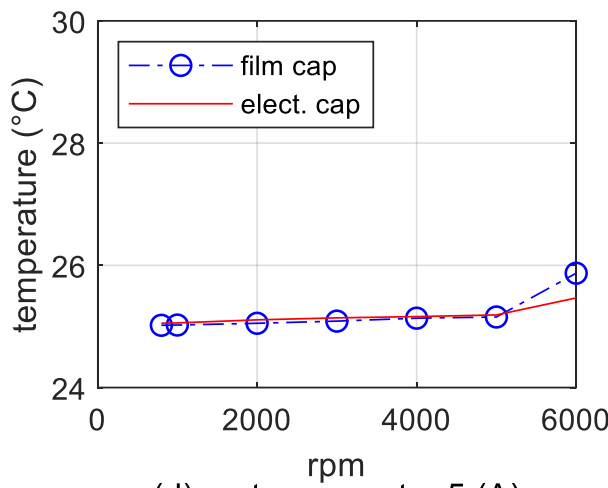

(d) motor current $=5(A)$

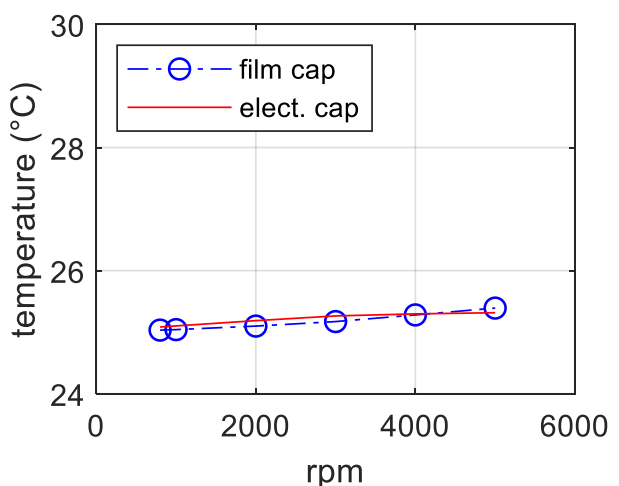

(f) motor current $=7$ (A)

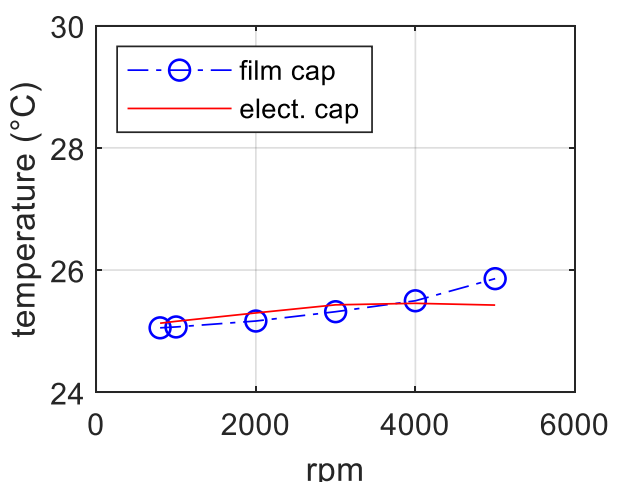

(h) motor current $=9(\mathrm{~A})$

Figure 25. Cont. 


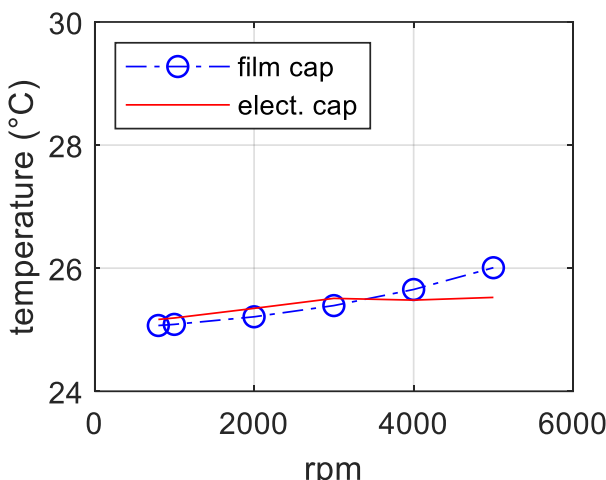

(i) motor current $=10(\mathrm{~A})$

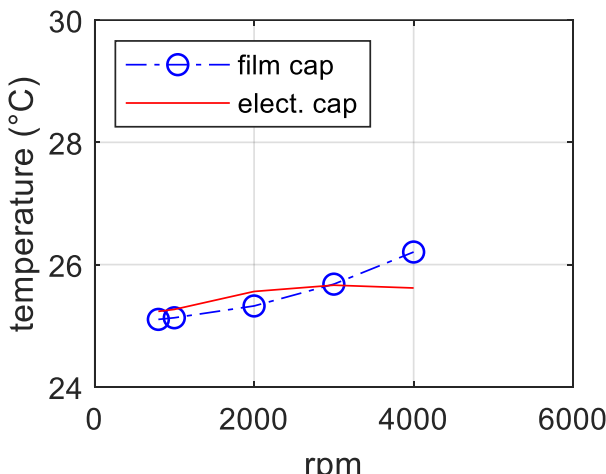

(k) motor current $=12(\mathrm{~A})$

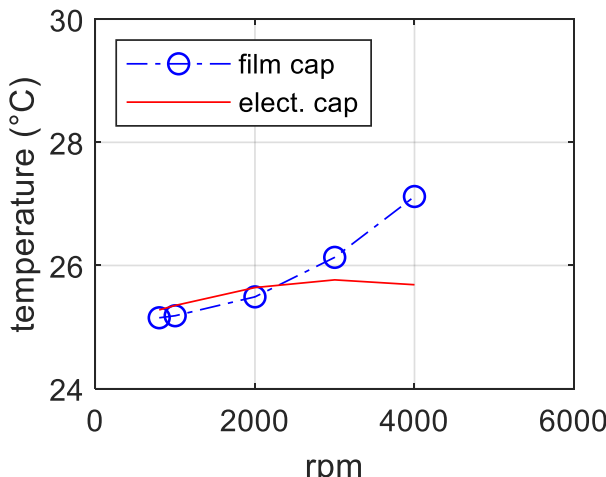

(m) motor current $=14(\mathrm{~A})$

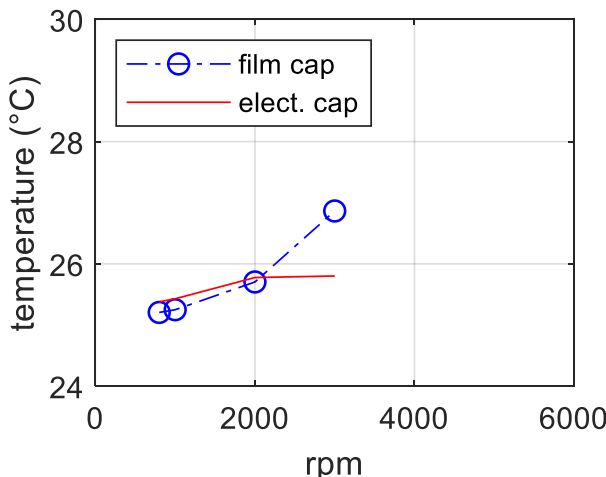

(o) motor current $=16(\mathrm{~A})$

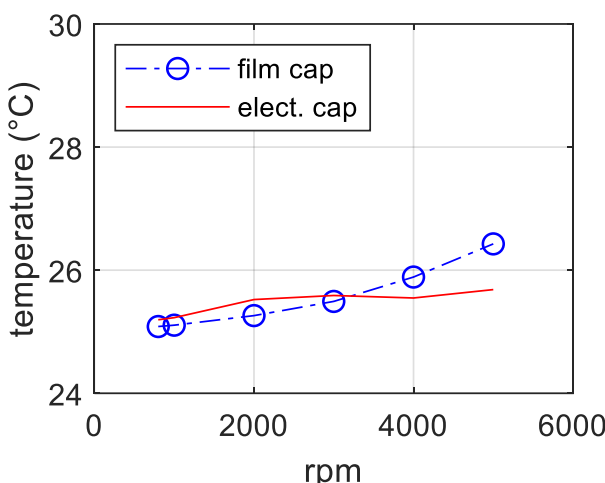

(j) motor current $=11(\mathrm{~A})$

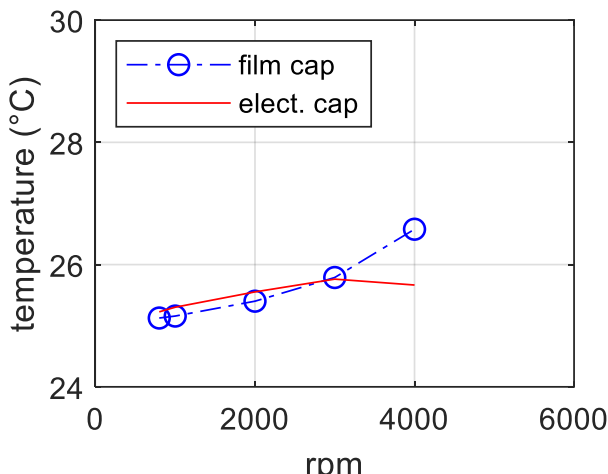

(I) motor current $=13(\mathrm{~A})$

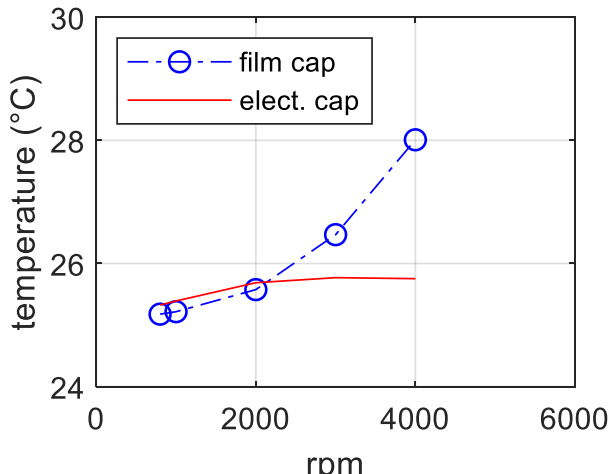

(n) motor current $=15(\mathrm{~A})$

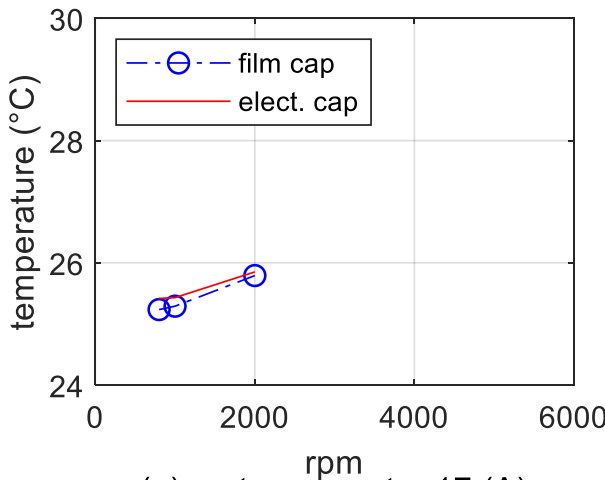

(p) motor current $=17(\mathrm{~A})$

Figure 25. Cont. 


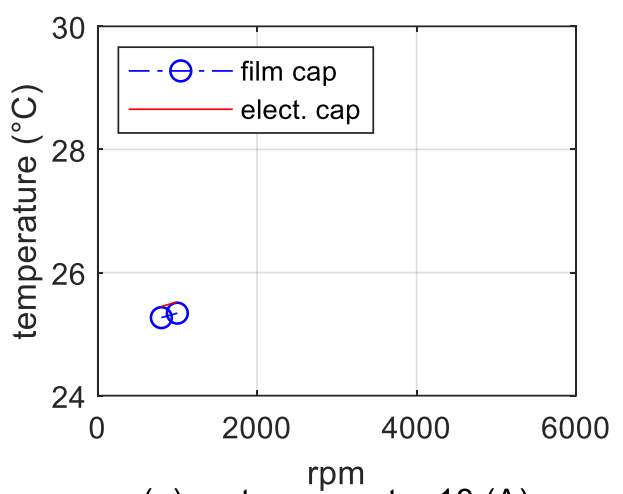

(q) motor current $=18(\mathrm{~A})$

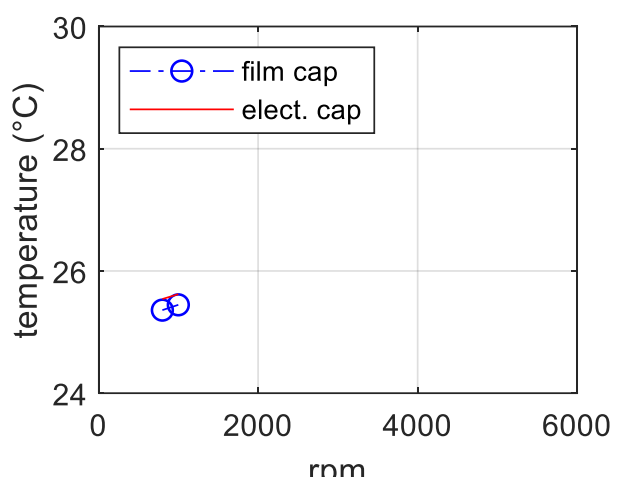

(s) motor current $=20(\mathrm{~A})$

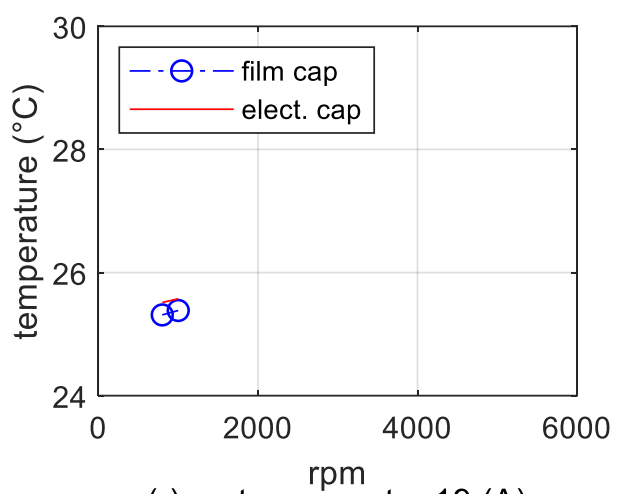

(r) motor current $=19(\mathrm{~A})$

Figure 25. Heat generation by the electrolytic and film capacitor as functions of the motor speed.

Table 9. Heat generation by the electrolytic and film capacitor at a speed range of 3000-6000 rpm.

\begin{tabular}{|c|c|c|c|c|c|c|c|c|}
\hline \multirow{2}{*}{$\begin{array}{l}\text { Speed (rpm) } \\
\text { Current (A) }\end{array}$} & \multicolumn{2}{|c|}{3000} & \multicolumn{2}{|c|}{4000} & \multicolumn{2}{|c|}{5000} & \multicolumn{2}{|c|}{6000} \\
\hline & $\begin{array}{l}\text { Film } \\
\left({ }^{\circ} \mathrm{C}\right)\end{array}$ & $\begin{array}{c}\text { Elect } \\
\left({ }^{\circ} \mathrm{C}\right)\end{array}$ & $\begin{array}{l}\text { Film } \\
\left({ }^{\circ} \mathrm{C}\right)\end{array}$ & $\begin{array}{l}\text { Elect } \\
\left({ }^{\circ} \mathrm{C}\right)\end{array}$ & $\begin{array}{l}\text { Film } \\
\left({ }^{\circ} \mathrm{C}\right)\end{array}$ & $\begin{array}{l}\text { Elect } \\
\left({ }^{\circ} \mathrm{C}\right)\end{array}$ & $\begin{array}{l}\text { Film } \\
\left({ }^{\circ} \mathrm{C}\right)\end{array}$ & $\begin{array}{l}\text { Elect } \\
\left({ }^{\circ} \mathrm{C}\right)\end{array}$ \\
\hline 1 & 25.01 & 25.02 & 25.01 & 25.02 & 25.01 & 25.03 & 25.22 & 25.13 \\
\hline 2 & 25.02 & 25.04 & 25.02 & 25.04 & 25.03 & 25.05 & 25.09 & 25.13 \\
\hline 3 & 25.03 & 25.06 & 25.04 & 25.07 & 25.05 & 25.08 & 25.14 & 25.14 \\
\hline 4 & 25.06 & 25.09 & 25.09 & 25.16 & 25.09 & 25.13 & 25.32 & 25.39 \\
\hline 5 & 25.09 & 25.14 & 25.14 & 25.16 & 25.15 & 25.19 & 25.87 & 25.47 \\
\hline 6 & 25.13 & 25.20 & 25.19 & 25.23 & 25.25 & 25.24 & N/A & $\mathrm{N} / \mathrm{A}$ \\
\hline 7 & 25.17 & 25.26 & 25.28 & 25.30 & 25.39 & 25.32 & N/A & N/A \\
\hline 8 & 25.26 & 25.34 & 25.40 & 25.37 & 25.54 & 25.39 & N/A & N/A \\
\hline 9 & 25.32 & 25.43 & 25.50 & 25.46 & 25.86 & 25.43 & N/A & N/A \\
\hline 10 & 25.39 & 25.51 & 25.65 & 25.48 & 26.01 & 25.52 & N/A & N/A \\
\hline 11 & 25.49 & 25.59 & 25.89 & 25.55 & 26.43 & 25.68 & N/A & N/A \\
\hline 12 & 25.68 & 25.66 & 26.21 & 25.62 & $\mathrm{~N} / \mathrm{A}$ & $\mathrm{N} / \mathrm{A}$ & N/A & N/A \\
\hline 13 & 25.79 & 25.76 & 26.58 & 25.67 & N/A & $\mathrm{N} / \mathrm{A}$ & N/A & N/A \\
\hline 14 & 26.13 & 25.77 & 27.12 & 25.69 & N/A & N/A & N/A & N/A \\
\hline 15 & 26.47 & 25.77 & 28.01 & 25.75 & N/A & N/A & N/A & N/A \\
\hline 16 & 26.87 & 25.80 & N/A & $\mathrm{N} / \mathrm{A}$ & N/A & N/A & N/A & N/A \\
\hline 17 & $\mathrm{~N} / \mathrm{A}$ & $\mathrm{N} / \mathrm{A}$ & N/A & N/A & N/A & N/A & N/A & N/A \\
\hline 18 & $\mathrm{~N} / \mathrm{A}$ & N/A & N/A & N/A & N/A & N/A & N/A & N/A \\
\hline 19 & N/A & N/A & N/A & $\mathrm{N} / \mathrm{A}$ & N/A & N/A & N/A & N/A \\
\hline 20 & $\mathrm{~N} / \mathrm{A}$ & $\mathrm{N} / \mathrm{A}$ & $\mathrm{N} / \mathrm{A}$ & N/A & N/A & $\mathrm{N} / \mathrm{A}$ & N/A & $\mathrm{N} / \mathrm{A}$ \\
\hline
\end{tabular}

\section{Conclusions}

This paper presented comprehensive comparisons and evaluations of electric compressors with two types of DC-link capacitors. Based on a $5 \mathrm{~kW}$ IPM motor drives and a VSI with a nominal DC 
voltage of $360 \mathrm{~V}$ for electric compressors, performances with electrolytic and film capacitors have been evaluated by experimental tests. Generally, the electric compressor system with the film capacitor based VSI showed better performance in comparison with the electric compressor system of the VSI with the electrolytic capacitor. The electric compressor system with the film capacitor based VSI showed lower power losses and lower peak-to-peak voltage fluctuation, and lower RMS values of DC-link voltage, than that with the electrolytic capacitor based VSI. However, the electric compressor system with the film capacitor exhibited higher percent RMS current value in the DC-link, in comparison with the electrolytic capacitor. This is because the capacitance of the film capacitor was about $10 \%$ of that of the electrolytic capacitor.

Author Contributions: Conceptualization, S.K.; methodology, N.K., S.K.; software, N.K.; validation, N.K., S.K. and J.B.; formal analysis, S.K.; investigation, N.K.; resources, N.K.; data curation, N.K., C.P.; writing-original draft preparation, N.K.; writing—review and editing, S.K.; visualization, C.P.; supervision, S.K.; project administration, S.K.; funding acquisition, S.K. All authors have read and agreed to the published version of the manuscript.

Funding: This research was supported by the National Research Foundation of Korea (NRF), grant funded by the Korean government (MSIT; 2020R1A2C1013413) and the Chung-Ang University Research Scholarship Grants in 2019.

Conflicts of Interest: The authors declare no conflict of interest.

\section{References}

1. Saber, A.Y.; Venayagamoorthy, G.K. Plug-in Vehicles and Renewable Energy Sources for Cost and Emission Reductions. IEEE Trans. Ind. Electron. 2011, 58, 1229-1238. [CrossRef]

2. Shariff, S.M.; Alam, M.S.; Ahmad, F.; Rafat, Y.; Asghar, M.S.J.; Khan, S. System Design and Realization of a Solar-Powered Electric Vehicle Charging Station. IEEE Syst. J. 2020, 14, 2748-2758. [CrossRef]

3. Chan, C.C.; Bouscayrol, A.; Chen, K. Electric, Hybrid, and Fuel-Cell Vehicles: Architectures and Modeling. IEEE Trans. Veh. Technol. 2010, 59, 589-598. [CrossRef]

4. Wang, H.; Blaabjerg, F. Reliability of Capacitors for DC-Link Applications in Power Electronic Converters-An Overview. IEEE Trans. Ind. Appl. 2014, 50, 3569-3578. [CrossRef]

5. Qin, Z.; Wang, H.; Blaabjerg, F.; Loh, P.C. Investigation into the control methods to reduce the DC-link capacitor ripple current in a back-to-back converter. In Proceedings of the 2014 IEEE Energy Conversion Congress and Exposition (ECCE), Pittsburgh, PA, USA, 14-18 September 2014; pp. 203-210. [CrossRef]

6. Sun, Y.; Wang, M.; Ran, L. Capacitance Monitoring Method for Metallized Polypropylene Film Capacitor in MMC. In Proceedings of the 2019 IEEE Sustainable Power and Energy Conference (iSPEC), Beijing, China, 21-23 November 2019; pp. 2431-2436. [CrossRef]

7. Shrivastava, A.; Azarian, M.H.; Pecht, M. Failure of Polymer Aluminum Electrolytic Capacitors under Elevated Temperature Humidity Environments. IEEE Trans. Compon. Packag. Manuf. Technol. 2017, 7, 745-750. [CrossRef]

8. Kirisken, B.; Ugurdag, H.F. Cost-Benefit Approach to Degradation of Electrolytic Capacitors. In Proceedings of the 2014 Reliability and Maintainability Symposium, Colorado Springs, CO, USA, 27-30 January 2014; pp. 1-6. [CrossRef]

9. Zou, C.; Zhang, N.; Kushner, D.; Orchard, R.; Mi, C.; Zhang, S. High Temperature Capacitors with High Energy Density. In Proceedings of the 2012 IEEE International Power Modulator and High Voltage Conference (IPMHVC), San Diego, CA, USA, 3-7 June 2012; pp. 419-421. [CrossRef]

10. Ji, H.; Guo, F.; Wang, Y.; Luo, X. Research Progress on Defrosting Strategy of Heat Pump System Heat Exchanger Outside for EV. In Proceedings of the 2019 2nd World Conference on Mechanical Engineering and Intelligent Manufacturing (WCMEIM), Shanghai, China, 4-6 December 2020; pp. 438-442. [CrossRef]

11. Woo, H.S.; Ahn, J.H.; Oh, M.S.; Kang, H.; Kim, Y. Study on the Heating Performance Characteristics of a Heat Pump System Utilizing Air and Waste Heat Source for Electric Vehicles. Korean J. Air-Cond. Refrig. Eng. 2013, 25, 180-186.

12. Choi, Y.; Lee, W.; Park, M.; Choi, Y. Heating Performance Evaluations for Development of Heat Pump System on Battery Electric Vehicle. KSAE Fall Conf. Proc. 2011, 1, 559-563.

13. Kondo, T.; Katayama, A.K.; Suetake, H.I.; Morishita, M.A. Development of Automotive Air-Conditioning Systems. Mitsubishi Heavy Ind. Tech. Rev. 2011, 48, 27-32. 
14. Antonijevic, D.; Heckt, R. Heat pump supplemental heating system for motor vehicles. J. Automob. Eng. 2004, 218, 1111-1115. [CrossRef]

15. Caldevilla, A.; Özbek, M.; Hünemörder, W.; Györög, T.; Hougard, E.; Pintea, M. Efficient Cabin and Powertrain Preconditioning for Evs with A Water-To-Water Heat Pump System. In Proceedings of the 2017 Twelfth International Conference on Ecological Vehicles and Renewable Energies (EVER), Monte Carlo, Monaco, 11-13 April 2017; pp. 1-5. [CrossRef]

16. Zhu, L.; Faller, W. An Integrated Electric Motor Driven Compressor Supported by Magnetic Bearings. In Proceedings of the 2019 IEEE International Electric Machines \& Drives Conference (IEMDC), San Diego, CA, USA, 12-15 May 2019; pp. 160-164. [CrossRef]

17. On Semiconductor, ASPM 27 Series 3-Phase 650 V, 50 A Automotive Smart Power Module. Available online: https://www.onsemi.com/pub/Collateral/NFVA35065L32-D.PDF (accessed on 31 November 2018).

18. Wen, H.; Xiao, W.; Wen, X.; Armstrong, P. Analysis and Evaluation of DC-Link Capacitors for High-Power-Density Electric Vehicle Drive Systems. IEEE Trans. Veh. Technol. 2012, 61, 2950-2964. [CrossRef]

19. TDK, Film Capacitors Metallized Polypropylene Film Capacitors. Available online: https://www.tdkelectronics.tdk.com/inf/20/20/ds/MKP_B32774XYZ_778XYZ.pdf (accessed on 2 August 2019).

20. Huesgen, T. Thermal Resistance of Snap-In Type Aluminum Electrolytic Capacitor Attached to Heat Sink. IEEE Trans. Ind. Appl. 2014, 50, 1198-1205. [CrossRef]

21. CDE, Aluminum Electrolytic Capacitor Application Guide. Available online: https://www.cde.com/resources/ catalogs/AEappGUIDE.pdf (accessed on 30 May 2020).

(C) 2020 by the authors. Licensee MDPI, Basel, Switzerland. This article is an open access article distributed under the terms and conditions of the Creative Commons Attribution (CC BY) license (http://creativecommons.org/licenses/by/4.0/). 